\title{
Probabilistic assessment of tunnel construction performance based on data
}

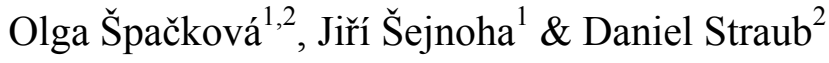 \\ ${ }^{1}$ Czech Technical University in Prague, Fac. of Civil Engineering (olga.spackova@fsv.cvut.cz, \\ sejnoha@fsv.cvut.cz) \\ ${ }^{2}$ Engineering Risk Analysis Group, Technical University Munich (straub@tum.de)
}

\begin{abstract}
A probabilistic model for estimating tunnel excavation time is learnt with data from past tunnel projects. The model is based on the Dynamic Bayesian Network technique. The model inputs are determined through an analysis of data from three tunnels built by means of the conventional tunneling method. The data motivate the development of a novel probability distribution to describe the excavation performance. In addition, the probability of construction failure events and the delay caused by such failures are estimated using databases available in the literature. The model is applied to a case study, in which it is demonstrated how observations from the tunnel construction process can be included to continuously update the prediction of excavation time.
\end{abstract}

\section{Keywords}

Construction time; tunnel construction risk; Dynamic Bayesian Networks; tunneling performance; failure rate. 


\section{Introduction}

Duration and cost of construction are key factors in decision making during the planning and design phase of a tunnel project. At present, construction time and cost are commonly assessed on a deterministic basis. The deterministic approach, however, does not appropriately reflect the uncertain reality. Systematic underestimation of construction costs related to infrastructure projects has been documented, for example in Flyvbjerg et al. (2004). Major losses and delays in tunnel construction projects have been reported by insurers (e.g. IMIA, 2006). The need for analyzing the uncertainty and risks of tunnel construction has been recognized by the tunneling community (see e.g. Lombardi 2001; Eskesen et al. 2004; Reilly 2005; ITIG 2006).

As shown in Isaksson and Stille (2005), the uncertainty in construction time and cost estimates results from the common variability of the construction performance and from the occurrence of extraordinary events (also denoted here as failures of the construction process) such as tunnel collapses. Risks resulting from construction failures are commonly analyzed separately using techniques such as fault tree or event tree analysis, decision trees or risk matrices (Benardos and Kaliampakos, 2004; Shahriar et al., 2008; Hong et al., 2009; Aliahmadi et al., 2011; Jurado et al., 2012). In Špačková (2012), tunnel construction failures are modeled by means of a Poisson process. Sousa and Einstein (2012) present a Dynamic Bayesian Networks (DBN) model, which estimates the expected utility as a sum of the expected costs and the risk of a tunnel collapse. The full probability distribution of the construction costs, however, is not assessed.

Some models allow one to probabilistically estimate the time or costs without taking into account the occurrence of extraordinary events. They typically use Monte Carlo (MC) simulation - see e.g. Ruwanpura and Ariaratnam (2007), Chung et al. (2006), Min (2008). Full probabilistic estimates of tunnel construction time or costs, taking into account both the common variability and the risk of extraordinary events, are presented in Isaksson and Stille (2005), Grasso et al. (2006) and Špačková and Straub (2012).

The probabilistic model inputs are mostly based on expert assessments. The description of geotechnical conditions is based on geological investigations, and the estimates of average advance rates and construction costs can be supported by simulations of the construction processes and by collected data (e.g. Kim and Bruland 2009; Burbaum et al. 
2005). However, little information is available on the random variability of the construction performance and on the failure rate. The available studies, e.g. those analyzing the Tunnel Boring Machine (TBM) penetration rate (Alvarez Grima et al., 2000; Sapigni M. et al., 2002; Chung et al., 2006), only capture a part of the uncertainty.

To the authors' knowledge, Flyvbjerg and COWI (2004) present the first study that quantifies the overall uncertainty in construction cost estimates based on an analysis of data from previous projects. However, since they assess only the cost overrun, the study is helpful for describing the present practice, but the results are not suitable for a probabilistic prediction of construction costs of future projects.

This paper aims to provide a framework for probabilistic prediction of tunnel construction time and presents a methodology for statistical analysis of data to determine the inputs for the probabilistic models. The data and the application example presented in this paper are limited to the conventional tunneling method, which is defined by ITA (2009) as "construction of underground openings of any shape with a cyclic construction process of: (1) excavation, by using the drill and blast methods or mechanical excavators except any full face TBM, (2) mucking and (3) placement of the primary support elements, such as steel ribs, rock bolts or sprayed concrete". Our approach might be extended to the modeling of mechanized tunneling with use of TBM.

A DBN model introduced in Špačková and Straub (2012) for the prediction of tunnel construction time is presented in Section 2. The DBN model serves as a basis for the analysis of the data presented in Section 3. This model facilitates the definition of the variables in the construction process model and their inter-dependencies. The model allows for efficient updating of the predictions based on observed geotechnical conditions and construction performance once construction has started; this facilitates the systematic, quantitative adaptation of the model estimates in real-time during the construction. The model takes into account both the common variability of construction process and the occurrence of extraordinary events. Additionally, it allows for modeling stochastic dependencies caused by common factors that systematically influence the construction process (such as human and organizational factors). The influence of stochastic dependencies on probabilistic estimates of construction time and costs has been discussed for example in Yang (2007) and Moret and Einstein (2011). 
A statistical approach to determining the probability distribution of unit time (time spent on excavating a segment of the tunnel with a given unit length, inverse of the advance rate) is presented in Section 3.1. The unit costs and activity durations (advance rates) are commonly modeled using uniform, triangular or beta distribution (Min, 2003; van Dorp, 2005; Yang, 2007; Said et al., 2009). Triangular and uniform distributions are especially popular, because experts feel generally comfortable in assessing upper and lower bounds and the mean/mode of random variables. Studies analyzing data from construction projects, however, show that other probabilistic models, such as the lognormal or Weibull distribution, are often more suitable (Chou, 2011). In this paper we suggest utilizing a combined probability distribution, which allows us to better represent the construction process influenced by different effects (normal performance and small disturbances). Data on excavation performance from three tunnels constructed in the Czech Republic are used. The influence of geotechnical conditions, tunnel geometry and construction method is examined. Furthermore, the correlation of the unit time along the tunnel axis is analyzed.

Section 3.2 presents a statistical approach to estimate failure rates and assess the probability distribution of delay caused by a failure.

Finally, the probabilistic estimation of the excavation time is shown in Section 4, using an example of one of the Czech tunnels. First, a prior estimate of the excavation time, which would be done in the planning phase of the project, is shown. Second, the prior prediction is updated with the excavation time observed during construction of the tunnel.

\section{Generic probabilistic model of tunnel construction process}

Construction of tunnels (as well as construction of other linear infrastructure projects) is a chain of repetitive activities whose order is in most cases pre-defined. It follows that there is negligible uncertainty in the determination of the critical path. From a modeling point of view, this is a significant advantage over the modeling of the construction process for other types of construction projects (Ökmen and Öztaş, 2008).

During the excavation, the tunnel construction process is adapted to the actual conditions encountered. The selected tunnel construction method (excavation technology, support 
pattern) and the corresponding speed and costs of construction depend primarily on the following factors:

- geological conditions (e.g. mechanical properties, frequency and orientation of discontinuities);

- hydrological conditions;

- frequency of changes of the geological and hydrological conditions (in)homogeneity of the environment;

- cross-section area of the tunnel;

- inclination of the tunnel;

- depth of the tunnel/height of overburden;

- affected structures and systems (requirements on maximal deformations, protection of water systems and environment, operational constraints).

The real construction performance is furthermore highly dependent on the planning and design of the tunnel and on the construction management and control.

The construction process is associated with many uncertainties and risks: (1) geotechnical uncertainties, resulting from limited knowledge and natural variability of the geotechnical conditions in the vicinity of the tunnel, (2) uncertainties in construction performance, which are associated with planning, organization and management of the construction process and variability of advance rate and construction costs, (3) risk of extraordinary events, i.e. events with low probability but potentially huge consequences such as tunnel collapse, fire or legal obstructions threatening the project.

All these uncertainties and risks should be taken into account when the construction costs or time are estimated. For this purpose, a DBN model is developed. The DBN is a special type of Bayesian Network (BN), which is suitable for modeling of stochastic processes. A brief introduction to BNs is provided in Appendix 1.

A generic probabilistic model of construction process is represented by the DBN shown in Figure 1. This generic model shows the basic principles and elements of modeling of the construction process. In a specific model, the geotechnical conditions, $G C$, construction performance, $C P$, as well as extraordinary events, $E E$, should be described in more detail by sets of random variables reflecting the tunnel specifics. An example of a 
specific DBN is shown later in the application example (Figure 10). The selection of the appropriate set of variables depends on local geological conditions, type of technology to be used, routines and experience of the owner, designer and contractor and on information available at the time of the estimate, i.e. on the project phase. The levels of detail in the (uncertainty) modeling of the various aspects of the process should be balanced. For example, a detailed model of geotechnical conditions is not necessarily beneficial for the time/cost prediction if it is not accompanied by a detailed model of the associated construction performance.

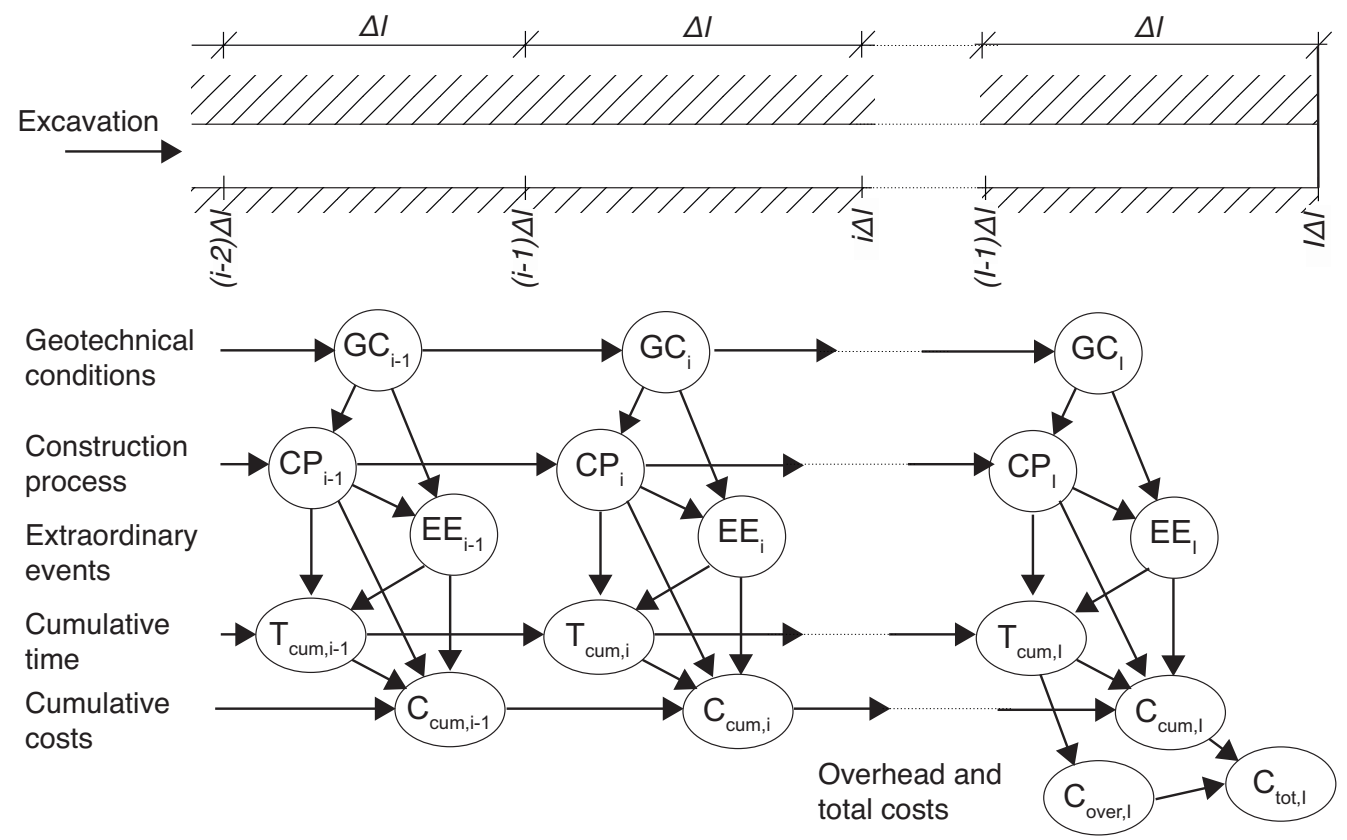

Figure 1. Generic DBN model for tunnel construction process. Detailed modeling of individual nodes is discussed in Secs. 2.1-2.3.

Each slice of the DBN in Figure 1 represents a tunnel segment of length $\Delta l$. In the following, the segment length $\Delta l$ is equal for all slices. The $i$ th slice of the DBN thus represents a tunnel segment between position $(i-1) \Delta l$ and $i \Delta l$. All variables are modeled as constant within a segment, i.e. the model implies that the geotechnical conditions and construction performance do not change within a segment. 


\subsection{Geotechnical uncertainties}

Here, uncertainty of geological and hydrological conditions is considered. For modeling purposes, the area of the tunnel is first divided into zones, in which the ground has homogeneous geotechnical properties. I.e. the properties are modeled as constant within this zone (as later shown in the application example in Section 4) or as a homogeneous stochastic process (as shown in Einstein, 1996 and in Špačková and Straub, 2012). The location of the zone boundaries is also modeled as uncertain.

The geotechnical conditions can be modeled at different levels of detailing: The selected variables can either represent individual properties of the ground (e.g. lithology, discontinuities, water content, presence of boulders) or they can correspond to a chosen geotechnical classification system such as RMR, Q-system or other project specific classification. For more details on geotechnical classification we refer to Bieniawski (1989) and Singh and Goel (1999).

A summarizing variable, denoted as ground class, is conditional on the other variables used for representing geotechnical conditions. The ground class has direct correspondence to the utilized technology of excavation, i.e. it should reflect all the geotechnical and hydrological conditions that influence the choice of construction method as discussed at the beginning of Section 2.

\subsection{Uncertainties in construction performance}

Uncertainty in the performance of tunnel construction is modeled by variables representing the tunnel geometry, construction method, human factor and unit time.

Geometry is a variable modelling the varying cross-section of the tunnel (e.g. typical cross-section vs. extended cross-section for emergency parking places). The variable can also be used to model inclination of the tunnel, special requirements on the excavation at the beginning and at the end of the tunnel or in the vicinity of other structures. The variable is deterministic if the tunnel design is final and no changes are expected.

The variable construction method represents the excavation technology, round length and support pattern. The construction method is selected based on the ground class and tunnel 
geometry. The construction method is in most cases defined deterministically for given ground class and geometry.

The variable human factor represents common factors, which systematically influence the construction process and thus introduce stochastic dependencies among the performance in each segment of the tunnel. These can be the quality of design and planning, the organization of construction works or other external influences not included in other model variables. The variable human factor can also be interpreted as the epistemic uncertainty, i.e. the uncertainty in selecting an appropriate probabilistic model (probability distribution) of unit time and failure rate, similar to the approach described in Cheung and Beck (2010) or Der Kiureghian and Ditlevsen (2009). To give an example, the selection of a less experienced construction company or a suboptimal technology of the excavation is likely to lead to slower and more variable excavation process in many or all segments of the tunnel. The quality of the construction company and the appropriateness of the technology are uncertain in the planning phase. The uncertainty in these common factors and the resulting uncertainty of the probabilistic model of unit time increase the uncertainty in the estimates of total construction time.

The human factor is supposed to be in the same state throughout the entire tunnel construction. This simple model reflects the fact that the influence of the common factors cannot be directly measured and can only be deduced from the average performance over long sections of the tunnel excavation. After the construction starts, the human factor can be updated based on observed performance.

The unit time $T$ represents the time spent for excavating a segment of the tunnel with a unit length $\Delta l$ excluding the extraordinary events. It corresponds to the inverse of the commonly used advance rate $A$. The unit time is dependent on the construction method and on the human factor. The probabilistic distribution of unit time can be assessed by experts, but preferably it should be based on analysis of data from other excavated tunnels as discussed in Section 3.1. A description of the unit time and advance rate modeled as a random process is presented in Appendix 2. 


\subsection{Extraordinary events (construction failures)}

Extraordinary events are defined as events that cause a delay longer than a threshold value (here selected equal to 15 days). Extraordinary events can represent cave-in collapses, tunnel flooding or severe legislative or public obstructions. These events can be interpreted as a failure of the construction process; we therefore use the terms extraordinary event and construction failure synonymously.

The probability of failure is dependent on the ground class and the human factor. It is calculated from the failure rate, i.e. the number of failures per unit length of the tunnel. The assessment of the failure rate is discussed in Section 3.2.2.

\subsection{Selection of the segment length}

Through the selection of the segment length $\Delta l$ represented by one slice of the DBN, assumptions on dependency of the variables along the tunnel axis are made. We assume that the changes of conditions can only occur between segments, i.e. the conditions are fully dependent within each segment.

For the modeling of geotechnical conditions, the finer the spatial discretization (i.e. the smaller $\Delta l$ ), the more precise is the model of the random changes of geology. Analogously, when modeling extraordinary events, we assume that only one failure can occur within each segment. The length of the segment $\Delta l$ must be selected short enough to justify this assumption.

On the other hand, when modeling the unit time and costs we assume that for a given ground class $G_{i}$ and human factor $H_{i}$, the unit time/costs in different segments become independent. As will be shown in Section 3.1, this assumption is not valid if the segment length $\Delta l$ is too small. Moreover, a finer spatial discretization is more computationally demanding.

Under these contradicting objectives, the optimum choice seems to be the minimal $\Delta l$ for which the assumption of independency of unit time and costs in different segments is justified. Moreover, if conventional tunneling is used, $\Delta l$ should not be selected shorter than the typical excavation cycle length, because the geotechnical conditions and construction performance are observed as an average for each cycle (Špačková and 
Straub, 2011). In the application presented in Section 4 , the segment length $\Delta l=5 \mathrm{~m}$ is used. The suitability of this choice is confirmed in Section 3.

\subsection{Evaluation of the DBN}

Evaluation of the DBN corresponds to calculating the marginal probability distributions of selected variables, in particular of the total construction time/costs. When new observations are available, e.g. from geological investigations or from the construction process itself, these calculations are performed conditionally on the observations. The choice of the inference algorithms for the evaluation of the DBN should depend on the complexity of the DBN, the type of random variables in the DBN (continuous, discrete), the required speed of the inference calculations and the required accuracy.

A comprehensive overview of inference algorithms is given for example in Murphy (2002). In general, every DBN can be evaluated by Monte Carlo (MC) simulation, as long as no or only limited Bayesian updating is considered (i.e., when no project-specific observations of the performance are included). In principle, advanced MC methods, such as Markov Chain Monte Carlo (MCMC) can overcome this limitation. Alternatively, for DBNs with discrete random variables, several exact algorithms exist. A modified Frontier algorithm, which is efficient for the evaluation of the proposed DBN is presented in Špačková and Straub (2012). This algorithm also allows one to efficiently update the model with the observed performance. It is implemented in the application presented in Section 4.

\section{Learning about construction performance from data}

It is proposed to categorize the performance of the excavation process in three classes:

(1) Normal performance, where the excavation round is commonly finished within one day; (2) small disturbances of the process associated with delays in the order of a few days; (3) extraordinary events, corresponding to cases when the excavation stopped for longer than 15 days. 
For completed and ongoing projects, the statistics of normal performance (1) and small disturbances (2) can be assessed from the observed excavation performance. Such analyses are presented in Section 3.1. For extraordinary events, statistical analysis is meaningful only if it is based on a larger dataset including a large number of tunnel projects, as presented in Section 3.2.

\subsection{Unit time}

The unit time $T$ is the time spent on excavating a segment of the tunnel with a given unit length $\Delta l$ under normal performance and small disturbances. A detailed discussion of the statistical properties of the unit time is given in Appendix 2. In this section, a statistical approach to determining the probability distribution of the unit time $T$ is presented and illustrated using data from three tunnels.

\subsubsection{Data}

Data on the construction progress from three tunnels built in the Czech Republic were collected for this analysis. The basic information on the tunnels is summarized in table Table 1. The sequencing of the tunnel heading used in analyzed tunnels is depicted in Figure 1. 
Table 1. Basic information on analyzed tunnels.

\begin{tabular}{|c|c|c|c|}
\hline Tunnel & TUN1 & TUN2 & TUN3 \\
\hline Type & $\begin{array}{c}\text { City road tunnel with } 2 \\
\text { (partly 3) lanes in each } \\
\text { tube }\end{array}$ & $\begin{array}{l}\text { City road tunnel with } 2 \\
\text { lanes in each tube }\end{array}$ & $\begin{array}{l}\text { Access and } \\
\text { technological tunnel for } \\
\text { construction of metro }\end{array}$ \\
\hline No. of tubes & 2 & 2 & 1 \\
\hline $\begin{array}{l}\text { Length of mined } \\
\text { sections }\end{array}$ & $2231+2224 \mathrm{~m}$ & $1060+1053 \mathrm{~m}$ & $491 \mathrm{~m}$ \\
\hline $\begin{array}{l}\text { Data available from } \\
\text { length }\end{array}$ & $1843+1543 \mathrm{~m}$ & $661+980 m$ & $480 \mathrm{~m}$ \\
\hline $\begin{array}{l}\text { Technology of } \\
\text { excavation }\end{array}$ & Conventional (NATM) & Conventional (NATM) & Conventional (NATM) \\
\hline Excavation sequencing & $\begin{array}{l}\text { Horizontal, partly vertical } \\
\text { sequencing (see Figure } \\
\text { 2) }\end{array}$ & $\begin{array}{l}\text { Vertical sequencing (see } \\
\text { Figure 2) }\end{array}$ & $\begin{array}{l}\text { Full face (see Figure } \\
2 \text { ) }\end{array}$ \\
\hline $\begin{array}{l}\text { Cross section area of } \\
\text { the tunnel tube }\end{array}$ & $124 / 174 \mathrm{~m}^{2}$ & $125 \mathrm{~m}^{2}$ & $37 / 43 / 46 \mathrm{~m}^{2}$ \\
\hline \multirow{2}{*}{$\begin{array}{l}\text { Cross section area of } \\
\text { the analyzed heading }\end{array}$} & $\sim 60 / \sim 85 \mathrm{~m}^{2}$ & \multirow[t]{2}{*}{$13 \mathrm{~m}^{2}$} & \multirow[t]{2}{*}{$37 / 43 / 46 \mathrm{~m}^{2}$} \\
\hline & $\begin{array}{c}\sim 30 / \sim 42 \mathrm{~m}^{2} \text { for vertical } \\
\text { sequencing }\end{array}$ & & \\
\hline $\begin{array}{l}\text { Number of } \\
\text { extraordinary events }\end{array}$ & $2+2$ & $1+1$ & 0 \\
\hline
\end{tabular}

TUN1

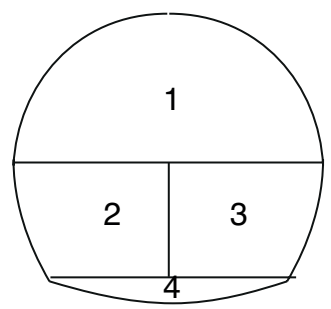

horizontal sequencing

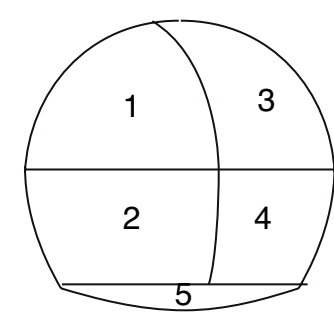

vertical sequencing

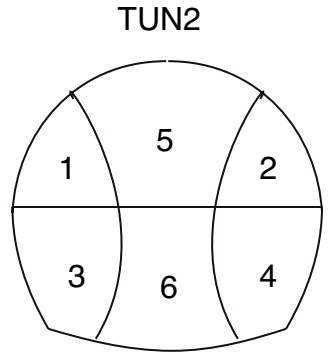

vertical sequencing

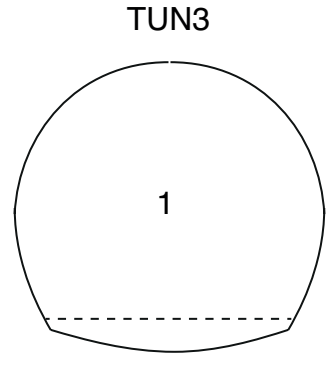

full face

Figure 2. Scheme of the excavation sequencing in the analyzed tunnels. The analyzed (leading) heading is number 1 . 
The tunnel TUN1 is one of the longest mined tunnels in the Czech Republic. It is built in a city and passes under a river and a railway line. The tunnel was driven through Ordovician rocks comprising of sandy and clayey shales, fine-grained quartzite and quartzose sandstone. The rock was hard to weakly weathered, and strongly tectonically affected with many fault zones. In some locations, the rock overburden was critically low (only $1.5 \mathrm{~m}$ ). The tunnel was mostly driven with crown-bench-invert pattern, in some sections a finer sequencing was used (see Figure 2). The maximal inflows of water were about 120 liters per second. Before excavation of the main tunnels, an exploration tunnel was built in the location of one of the future tubes.

The mining of the final tunnel proceeded from one portal. Two cave-in collapses occurred within a short section of one of the tubes. The second collapse stopped the works also on the other tube. The accidents resulted in a total delay of approximately one year. In the most critical section of the tunnel with minimal height of rock overburden, high inflow of water and blocky jointed rock, the round length was reduced to $0.8 \mathrm{~m}$ and forepoling was used to improve the stability of the system. After the collapses occurred, jet grounting from the surface and chemical grouting was applied and additional monitoring was prescribed.

The tunnel TUN2 was built under a densely developed area. It was driven through homogenous geotechnical environment consisting of Neogene clays covered by anthropogenic fills. The clays are stiff and locally hard. They are highly plastic and, in combination with water, extremely squeezing. The total overburden ranged from 6 to 21 $\mathrm{m}$, a minimum thickness of the clay layer of 2-3 $\mathrm{m}$ above the tunnel crown was ensured in all positions of the tunnel.

The mining of the tunnel proceeded from one portal, just a short section at the other end of the tunnel was excavated in the opposite direction. To minimize the surface deformation, partial excavation with side drifts was used in the whole tunnel (see Figure 2). Minimal distance between each heading was prescribed to be $6 \mathrm{~m}$. The round length in each of the cells was $1 \mathrm{~m}$. Auxiliary measures, such as a pipe umbrella, were used. In the analyzed sections of the tunnel, two extraordinary events occurred which stopped the construction of the main tunnel heading for 17 and 31 days, respectively. 
The last analyzed tunnel, TUN3 with a total length of $480 \mathrm{~m}$, was built within a metro line extension project. The tunnel was mined in homogeneous sandstones and claystones under the water table. The length of excavation cycles varied from 1 to $2 \mathrm{~m}$ depending on the geotechnical conditions. No unexpected events occurred during the excavation.

In all three tunnels, inspections of geotechnical conditions at the tunnel heading and controls of construction performance were made regularly, commonly at the end of each round. From these records we obtained the following data:

- Date of the inspection

- Position of the main tunnel heading at this time

- Classification of the geotechnical conditions in the vicinity of the tunnel heading in ground classes, which serve as the basis for selecting the construction method (support pattern) and for pricing and progress payments. A brief characterization of ground classes used in the Czech Republic and their representation in the studied tunnels is summarized in Table 2. A comparison of the classification methods used in the Czech Republic with the broadly known RMR and Q-system can be found in Barták and Makásek (2011) and (Špačková, 2012).

- Short descriptions of extraordinary events, when the excavation was stopped for more than 15 days. 
Table 2. Characterization of ground classes (NATM technological classes) and their share in the analyzed tunnels.

\begin{tabular}{|c|c|c|c|c|c|c|c|c|}
\hline \multirow{3}{*}{$\begin{array}{l}\text { Gro } \\
\text { und } \\
\text { class }\end{array}$} & \multirow{2}{*}{\multicolumn{3}{|c|}{ Characterization of ground classes }} & \multicolumn{5}{|c|}{ Length of sections belonging to the class } \\
\hline & & & & \multicolumn{2}{|c|}{ TUN1 } & \multicolumn{2}{|c|}{ TUN2 } & \multirow[t]{2}{*}{ TUN3 } \\
\hline & Stability & $\begin{array}{l}\text { Round } \\
\text { length }\end{array}$ & $\begin{array}{l}\text { Sequencing; primary } \\
\text { support }\end{array}$ & $1^{\text {st }}$ tube & $2^{\text {nd }}$ tube & $1^{\text {st }}$ tube & $2^{\text {nd }}$ tube & \\
\hline 1 & $\begin{array}{c}>2 \\
\text { weeks }\end{array}$ & Unlimited & Not needed & 0 & 0 & 0 & 0 & 0 \\
\hline 2 & $\begin{array}{c}2 \text { days } \\
-2 \text { weeks }\end{array}$ & $>2.5 \mathrm{~m}$ & $\begin{array}{l}\text { Horizontal seq.; bolts }+ \\
50-100 \mathrm{~mm} \text { shotcrete }\end{array}$ & 0 & 0 & 0 & 0 & 0 \\
\hline 3 & $\begin{array}{l}2 \text { hours } \\
-2 \text { days }\end{array}$ & $1.5-2.5 \mathrm{~m}$ & $\begin{array}{l}\text { Horizontal seq.; bolts, } \\
\text { shotcrete }+ \text { mesh }\end{array}$ & $\begin{array}{c}808 \mathrm{~m} \\
44 \%\end{array}$ & $\begin{array}{c}706 \mathrm{~m} \\
46 \%\end{array}$ & 0 & 0 & $\begin{array}{c}156 \mathrm{~m} \\
33 \%\end{array}$ \\
\hline 4 & $<2$ hours & $1-1.5 \mathrm{~m}$ & $\begin{array}{l}\text { Horizontal ev. Vertical } \\
\text { seq.; girders, ribs, } \\
\text { shotcrete + auxiliary; } \\
\text { closure of support ring }\end{array}$ & $\begin{array}{c}618 \mathrm{~m} \\
33 \%\end{array}$ & $\begin{array}{l}230 \mathrm{~m} \\
22 \%\end{array}$ & $\begin{array}{l}596 \mathrm{~m} \\
90 \%\end{array}$ & $\begin{array}{c}843 \mathrm{~m} \\
86 \%\end{array}$ & $\begin{array}{c}289 \mathrm{~m} \\
60 \%\end{array}$ \\
\hline 5 & $\begin{array}{l}\text { unstable } \\
\text { ground }\end{array}$ & $<1 \mathrm{~m}$ & $\begin{array}{l}\text { Horizontal an vertical } \\
\text { seq.; girders, ribs, } \\
\text { shotcrete + auxilary; } \\
\text { closure of support ring }\end{array}$ & $\begin{array}{c}417 \mathrm{~m} \\
23 \%\end{array}$ & $\begin{array}{c}497 \mathrm{~m} \\
32 \%\end{array}$ & $\begin{array}{l}65 \mathrm{~m} \\
10 \%\end{array}$ & $\begin{array}{c}137 \mathrm{~m} \\
14 \%\end{array}$ & $\begin{array}{l}35 \mathrm{~m} \\
7 \%\end{array}$ \\
\hline
\end{tabular}

Only the progress of the main tunnel heading (denoted as 1 in Figure 2) is studied because it has decisive influence on the overall excavation performance. As an example, the excavation progress in tube 1 of TUN1 is depicted in Figure 3. The two extraordinary events can be clearly identified in the chart. 


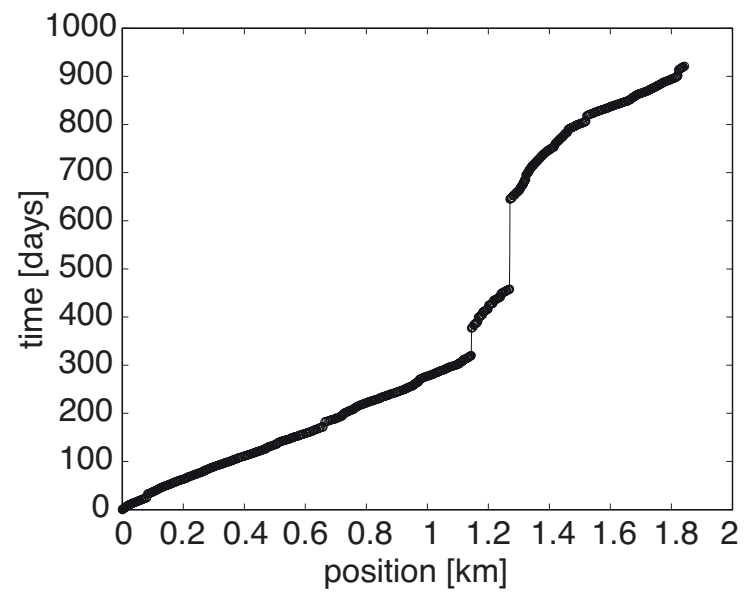

Figure 3. Excavation progress in the 1st tube of the tunnel TUN1.

\subsubsection{Statistical estimation}

For the statistical analysis, we follow the modeling framework provided by the DBN. Therein, unit time $T$ is the time for excavation of a segment with length $\Delta l$. It is dependent on the construction method (i.e. on combination of ground class and geometry). For a given construction method, the unit time is a stationary random process (see also Appendix 2).

Following the DBN model framework, the unit time is furthermore dependent on the human factor. It is recalled that the human factor characterizes the deviation of the actual performance from the estimated performance. In the DBN model, the human factor is assumed to be constant throughout the whole tunnel. Based on the data alone, i.e. without knowledge of the original estimate, it is not possible to determine the human factor. Therefore, the dependence on human factor is not explicitly included in the data analysis.

In the analysis, a segment length $\Delta l=5 \mathrm{~m}$ was selected. Because the records were not made at the boundaries of the segments, the unit time observed in the $i$ th segment of the tunnel, denoted as $\widehat{T}_{i}$, was calculated by a linear interpolation of the observed data as illustrated in Figure 4. 


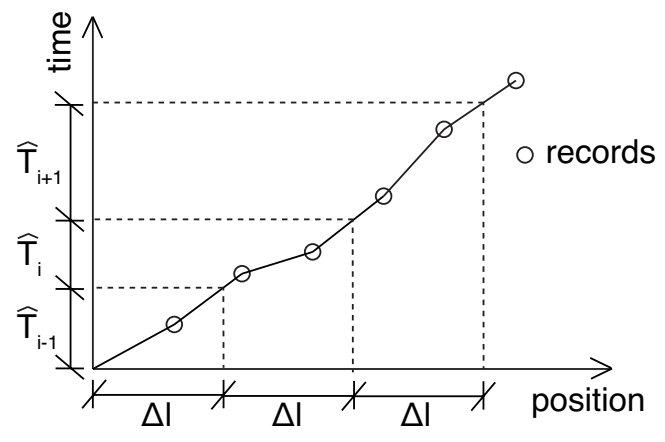

Figure 4. Determining the observed unit times $\widehat{T}_{i}$ from the data with linear interpolation.

The variability of the observed unit time $\widehat{T}_{l}$ per $5 \mathrm{~m}$ in different locations along the $1^{\text {st }}$ tube of the tunnel TUN1, after excluding the extraordinary events, is depicted in Figure 5.

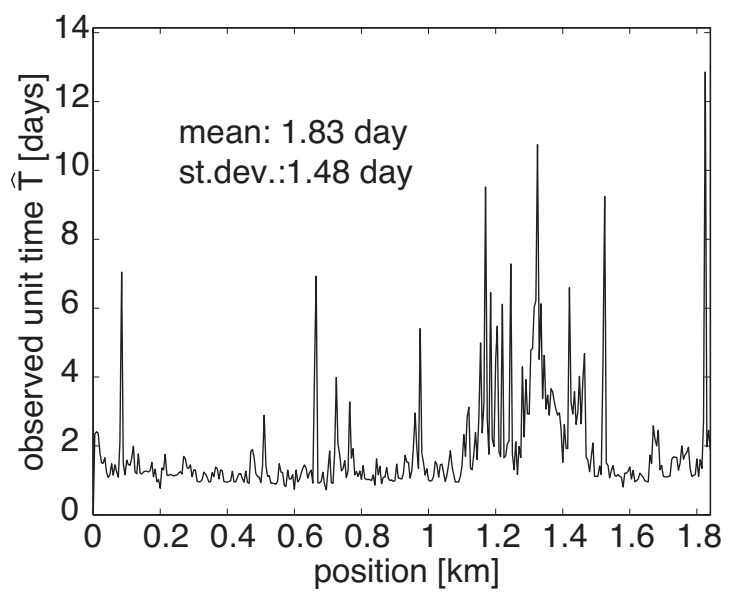

Figure 5. Observed unit time $\widehat{T}_{i}$ per $5 \mathrm{~m}$ at different positions of the tube 1 of tunnel TUN1 after excluding the extraordinary events.

The probabilistic model of the unit time $T$ must include both the normal performance (1) and small disturbances (2). Given normal performance, the unit time is described using a probability density function (PDF) $f_{T_{N}}$, given small disturbances it is described using a $\operatorname{PDF} f_{T_{D}}$. Furthermore, let $p$ be the probability of normal performance in a segment; consequently the probability of small disturbances is $1-p$. Following the total probability theorem, the PDF of the unit time including both (1) and (2) is:

$$
\begin{gathered}
f_{T}(t)=\operatorname{Pr}(\text { normal p. }) * f(t \mid \text { normal } p .)+\operatorname{Pr}(\text { small } d .) * f(t \mid \text { small } d .) \\
=p * f_{T_{N}}(t)+(1-p) * f_{T_{D}}(t) .
\end{gathered}
$$


From the data one cannot clearly distinguish between the normal performance and small disturbances. If this was possible, we could calculate the probability $p$ as the share of normal performance on the whole sample and fit common probabilistic models, $f_{T_{N}}(t)$ and $f_{T_{D}}(t)$, to the classified data. To avoid this manual classification, we use a probabilistic approach and we fit directly the combined probabilistic model following Eq. (1):

$f_{T}(t ; p, \mu, \sigma, a, b)=p * f_{T_{N}}(t ; \mu, \sigma)+(1-p) * f_{T_{D}}(t ; a, b)$,

where $f_{T_{N}}(t ; \mu, \sigma)$ is here modeled as a lognormal PDF with parameters $\mu, \sigma$ and $f_{T_{D}}(t ; a, b)$ as a beta PDF with parameters $a, b$, bounded from 0 to 15 days. The parameters $p, \mu, \sigma, a, b$ are estimated by means of the maximum likelihood method (Benjamin and Cornell, 1970).

The lognormal and beta distribution are commonly used in the literature for representing uncertainties in construction time and costs (Chou, 2011). The left bounded lognormal distribution describes well the normal performance, which has mean close to zero, relatively small variance and is slightly skewed. The beta distribution is suitable for the small disturbances, which have much higher variance and following the definition in our model framework are bounded between 0 and 15 days. However, the model of Eq. (2) is also valid with other distribution types for $f_{T_{N}}$ and $f_{T_{D}}$.

Example PFDs and CDFs for tunnel TUN1 and ground class 5 are shown in Figure 6. 

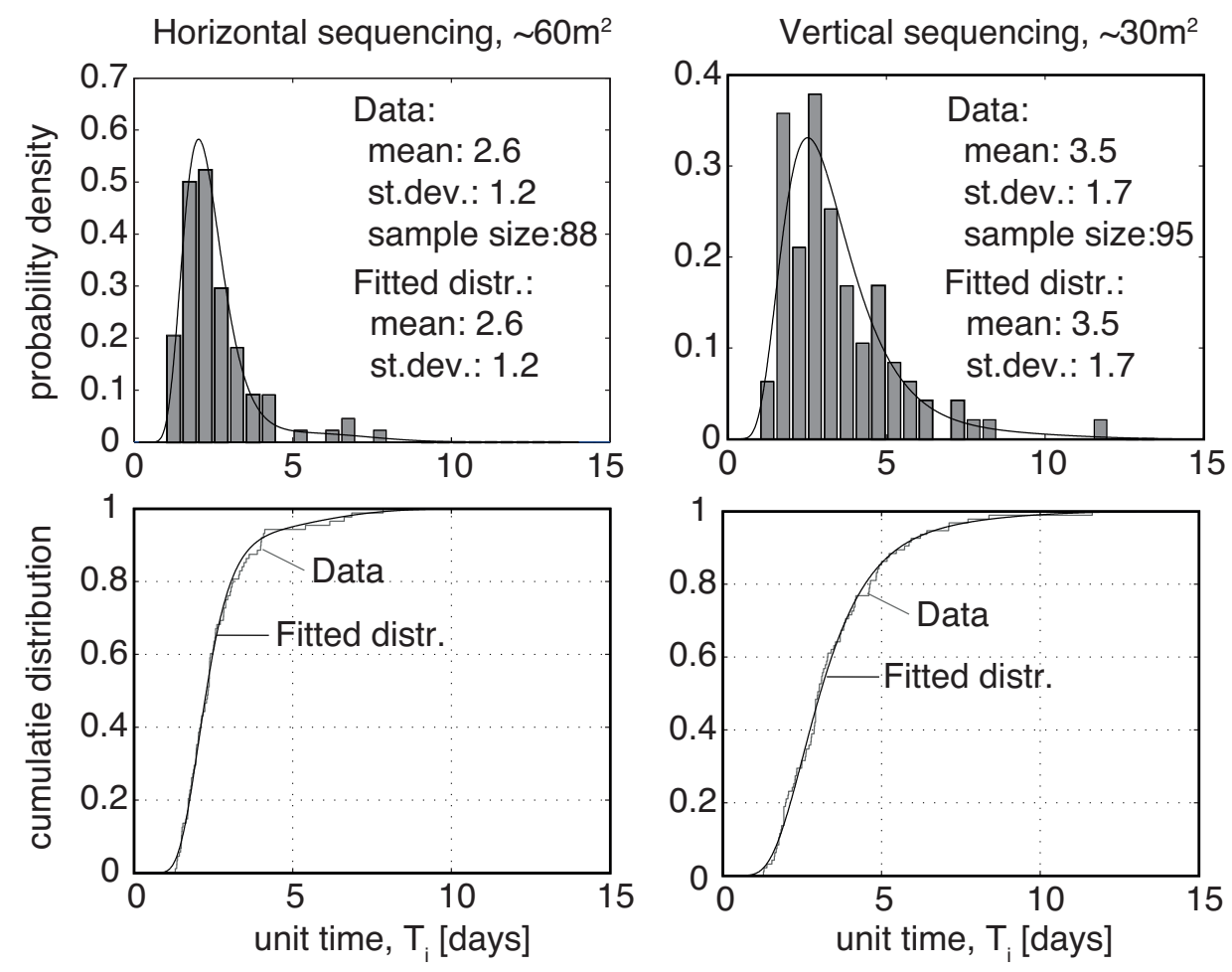

Figure 6. Fitted PDFs and CDFs of unit time T per $5 m$ for tunnel TUN1, ground class 5 , for different sequencing of the tunnel heading.

The means and coefficients of variation (c.o.v.) of the unit time $T$ for particular construction methods calculated directly from data are summarized in the first part of Table 3. The second and third part of Table 3 show the means and c.o.v. of the two components of the unit time: the normal performance described by $f_{T_{N}}(t ; \mu, \sigma)$ and small disturbances described by $f_{T_{D}}(t ; a, b)$. These values are determined from the fitted distributions. The fourth part of the table shows the probability $p$ of normal performance and the last part of the table summarizes the number of tunnel segments with length $\Delta l=5 m$, where the construction method was used (i.e. the sample size). 
Table 3. Fitted probability model of unit time $T$ per $5 \mathrm{~m}$ of the tunnel tube in [days] - summary of mean values and coefficients of variation (in parentheses) for different ground classes, crosssection areas and excavation sequencing.

\begin{tabular}{|c|c|c|c|c|c|c|c|c|}
\hline & \multirow{2}{*}{\begin{tabular}{|l} 
Tunnel \\
Sequencing
\end{tabular}} & \multicolumn{3}{|c|}{ TUN1 } & \multirow{2}{*}{$\begin{array}{c}\text { TUN2 } \\
\text { Vertical }\end{array}$} & \multirow{2}{*}{\multicolumn{3}{|c|}{$\begin{array}{c}\text { TUN3 } \\
\text { Full face }\end{array}$}} \\
\hline & & Horizontal & Vertical & Horizontal & & & & \\
\hline & $\begin{array}{l}\text { Area } \\
\text { Ground } \\
\text { class }\end{array}$ & $\sim 60 \mathrm{~m}^{2}$ & $\sim 30 \mathrm{~m}^{2}$ & $\sim 85 \mathrm{~m}^{2}$ & $13 \mathrm{~m}^{2}$ & $37 \mathrm{~m}^{2}$ & $43 \mathrm{~m}^{2}$ & $46 \mathrm{~m}^{2}$ \\
\hline \multirow{3}{*}{$\begin{array}{l}\text { Both } \\
\text { component } \\
\text { s }\end{array}$} & 3 & $1.4(0.5)$ & $1.9(1.1)$ & $1.9(1.1)$ & - & $1.5(0.4)$ & $1.9(0.5)$ & $0.9(0.1)$ \\
\hline & 4 & $1.4(0.5)$ & $2.0(1.2)$ & $2.0(0.2)$ & $3.2(0.6)$ & $1.6(0.1)$ & $2.4(1)$ & $2.1(0.7)$ \\
\hline & 5 & $2.6(0.5)$ & $3.5(0.5)$ & - & $3.7(0.5)$ & $2.1(0.3)$ & - & $3.0(1.0)$ \\
\hline \multirow{3}{*}{$\begin{array}{l}\text { Normal } \\
\text { perform. } \\
f_{T_{N}}(t ; \mu, \sigma)\end{array}$} & 3 & $1.2(0.2)$ & $1.5(0.2)$ & $1.5(0.2)$ & - & $1.4(0.3)$ & $1.4(0.1)$ & $1.0(0.2)$ \\
\hline & 4 & $1.3(0.2)$ & $1.5(0.2)$ & $2.0(0.2)$ & $2.9(0.6)$ & $1.6(0.1)$ & $1.6(0.1)$ & $1.5(0.2)$ \\
\hline & 5 & $2.3(0.3)$ & $3.3(0.4)$ & - & $3.1(0.3)$ & $1.6(0.0)$ & - & $1.2(0.1)$ \\
\hline \multirow{3}{*}{$\begin{array}{l}\text { Small } \\
\text { disturbanc } \\
\text { es } \\
f_{T_{D}}(t ; a, b)\end{array}$} & 3 & $3.2(0.6)$ & $11.3(0.1)$ & $12.3(0.1)$ & N/A & $3.2(0.3)$ & $3.5(0.3)$ & $1.0(0.6)$ \\
\hline & 4 & $3.2(0.5)$ & $12.0(0.4)$ & $2.3(0.4)$ & $4.3(0.25)$ & $1.8(0.1)$ & $7.5(0.5)$ & $5.2(0.2)$ \\
\hline & 5 & $5.8(0.3)$ & $6.8(0.4)$ & - & $8.1(0.2)$ & $2.7(0.0)$ & - & $8.3(0.2)$ \\
\hline \multirow{3}{*}{$\begin{array}{l}\text { Prob. of } \\
\text { normal } \\
\text { perf. }(p)\end{array}$} & 3 & 0.93 & 0.95 & 0.95 & N/A & 0.93 & 0.75 & 0.95 \\
\hline & 4 & 0.95 & 0.95 & 0.95 & 0.79 & 0.95 & 0.87 & 0.83 \\
\hline & 5 & 0.93 & 0.95 & - & 0.87 & 0.55 & N/A & 0.75 \\
\hline \multirow{3}{*}{$\begin{array}{l}\text { Sample } \\
\text { size }\end{array}$} & 3 & 245 & 28 & 28 & 0 & 19 & 4 & 8 \\
\hline & 4 & 138 & 45 & 9 & 286 & 3 & 47 & 6 \\
\hline & 5 & 88 & 95 & 0 & 41 & 4 & 0 & 4 \\
\hline
\end{tabular}

The performance of the excavation in TUN1 and TUN3 is relatively similar. Even if the total cross-section area of the two tunnels is different, the leading tunnel heading allows utilization of high-performance machinery and the geotechnical conditions are similar. A difference can be observed in the excavation of TUN2, where the progress is significantly slower (i.e. the mean unit time is higher). TUN2 is excavated in difficult geotechnical conditions requiring complicated excavation sequencing and support measures. The leading tunnel heading has a cross-sectional area of only $13 \mathrm{~m}^{2}$, the utilized machinery is therefore less efficient and the installation of support measures is demanding.

The c.o.v. for the normal performance is in most cases in the range of $0.1-0.3$. A higher c.o.v. can be observed in TUN2 and in case of vertical sequencing in TUN1. This indicates that for demanding excavation technologies, the variability of the performance is increased. 
Excluding the cases for which the sample size is insufficient, we can conclude that the probability of normal performance, as expressed by the parameter $p$, is in the order of 0.8 to 0.95 .

The data basis is not sufficient for reliably estimating the parameters of $f_{T_{D}}$. Nevertheless, the analysis shows that the small disturbances can explain the difference between the c.o.v. of the observed unit time and the c.o.v. of the normal performance. The latter is the value that most experts would estimate; these value underestimates the real construction time by more than $10 \%$.

\subsubsection{Correlation analysis}

In addition to assessing the marginal distribution of unit time, it is necessary to analyze the correlation of construction performance among different locations. For this analysis, samples of the unit time per $1 \mathrm{~m}$ of tunnel tube, denoted as $T_{1 m}$, are obtained using the procedure illustrated in Figure 4. The sample coefficient of correlation of the unit time $T_{1 m}$ for two segments at a distance $\tau$ is calculated as:

$R(\tau)=\frac{\frac{1}{n_{\tau}} \sum_{i=1}^{n_{\tau}}\left(\widehat{T}_{1 m, i}-m_{T_{1 m}}\right)\left(\widehat{T}_{1 m, i+\tau}-m_{T_{1 m}}\right)}{s_{T_{1 m}}^{2}}$

where $m_{T_{1 m}}$ and $s_{T_{1 m}}$ are the sample mean and standard deviation of $T_{1 m}, \widehat{T}_{1 m, i}$ is the unit time observed at position $i$ and $\widehat{T}_{1 m, i+\tau}$ is the unit time observed at position $i+\tau$. $n_{\tau}$ is the number of observations of pairs $\widehat{T}_{1 m, i}$ and $\widehat{T}_{1 m, i+\tau}: n_{\tau}=L-\tau$, with $L$ being the length of the tunnel tube excavated with a given construction method.

A power-exponential function is fitted to the coefficients of correlation calculated for different distances $\tau$ using Eq. (3). The function is:

$\rho_{T}(\tau)=\exp \left(-a \tau^{b}\right)$

where $a$ and $b$ are the parameters to be fitted. $\rho_{T}(\tau)$ is a correlation function (Vanmarcke, 1983). Other correlation functions were investigated, but the power-exponential function was found to best describe the data from the analyzed tunnels. 
Figure 7 depicts the observed correlation functions for unit time in ground class 4 estimated from the data.

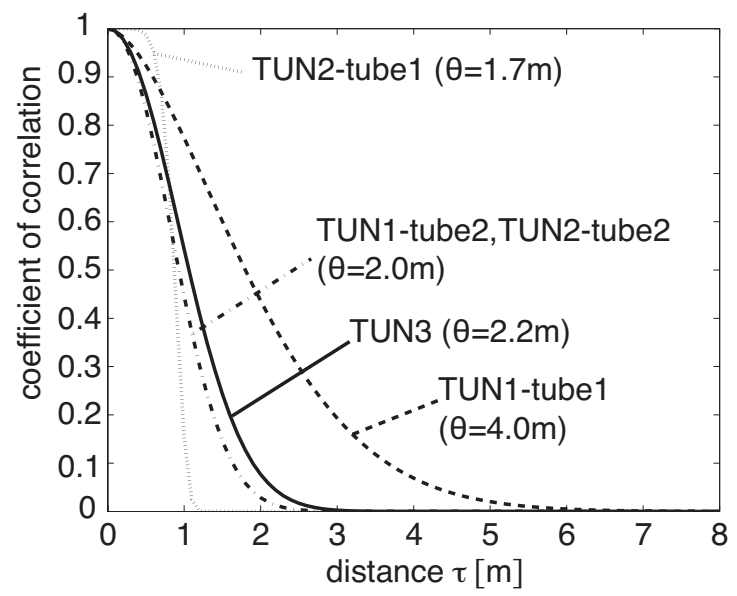

Figure 7. Correlation function $\rho_{T}(\tau)$ of unit time for ground class 4 in different tunnels. The function represents the correlation of unit time at two locations in the tunnel with distance $\tau$. The numbers in parentheses show the scale of fluctuation, $\theta$.

As evident from Figure 7, the coefficient of correlation approaches zero already for $\tau \cong 5 \mathrm{~m}$, indicating that the unit times observed at a distance of more than $5 \mathrm{~m}$ are uncorrelated for a given ground class. To objectively evaluate the distance at which the unit time becomes uncorrelated, the scale of fluctuation is calculated:

$\theta=2 \int_{0}^{\infty} \rho_{T}(\tau) d \tau$

The scale of fluctuation is used instead of the more common correlation length, because unlike the latter its definition is independent of the utilized correlation function (Vanmarcke, 1983). The observed scales of fluctuation for different tunnels and ground classes are summarized in Table 4. 
Table 4. Scale of fluctuation of unit time, $\theta$, for different tunnels and ground classes.

\begin{tabular}{cccccc}
\hline \multirow{2}{*}{$\begin{array}{c}\text { Tunnel } \\
\text { Tube }\end{array}$} & tube 1 & tube 2 & tube 1 & TUN2 & TUN3 \\
& \multicolumn{5}{c}{ tube 2 } \\
Ground class & \multicolumn{5}{c}{ Scale of fluctuation, $\theta$, in [m] } \\
\hline 3 & 3.7 & 3.3 & - & - & 2.4 \\
4 & 4.0 & 2.0 & 1.7 & 2.0 & 2.2 \\
5 & 3.7 & 5.2 & 1.7 & 1.9 & 2.0 \\
All classes & 43.5 & 30.9 & 1.6 & 1.9 & 2.3 \\
\hline
\end{tabular}

When analyzing the data from all ground classes jointly, large scale of fluctuation would be expected: the tunnel segments which are nearby are more likely to belong to the same ground class and thus to have correlated unit time. This effect can, however, only be observed in TUN1, because in case of TUN2 and TUN3 the performances in different ground classes exhibit smaller differences, as can be observed in Table 3.

With known correlation function, it is possible to assess the mean and standard deviation of the unit time for any segment length $\Delta l$, following the procedure described in Appendix 2, Eqs. (20) and (21). As an example, the mean and standard deviation of $T$ (corresponding to a segment length $\Delta l=5 \mathrm{~m}$ ) are determined from the mean and standard deviation of $T_{1 m}$ through the following relationships:

$m_{T}=5 * m_{T_{1 m}}$

$s_{T}=5 s_{T_{1 m}} \sqrt{\frac{\gamma(5)}{\gamma(1)}}$

where $\gamma($.$) is the so-called variance function (Vanmarcke, 1983) described in Eq. (22),$ which depends on the fitted correlation function $\rho_{T}(\tau)$. Alternatively, the variance function can be approximated using the observed correlation $R(\tau)$ for discrete values of $\tau=1 \mathrm{~m}, 2 \mathrm{~m}, \ldots$ according to Eq. (3) by 
$\gamma(\Delta l)=\frac{1}{\Delta l^{2}} \sum_{i=1}^{\Delta l} \sum_{j=1}^{\Delta l} R(|i-j|)$

To demonstrate the validity of the above relations, we compare the sample means and standard deviations of unit time per $5 \mathrm{~m}, m_{T}$ and $s_{T}$, obtained directly from data, with the means and standard deviations calculated from $m_{T_{1 m}}$ and $s_{T_{1 m}}$ using Eq. (6) and Eq. (7). This comparison is given in Table 5 for the tube 1 of tunnel TUN1.

Table 5. Means and standard deviations of unit time in tube 1 of TUN1, in [days] - comparison of values obtained from data and calculated using Eq. (6) and Eq. (7).

\begin{tabular}{ccccccc}
\hline & \multicolumn{2}{c}{$\begin{array}{c}\text { Unit time per 1m } \\
\text { From data }\end{array}$} & \multicolumn{2}{c}{$\begin{array}{c}\text { Unit time per 5m } \\
\text { Calculated }\end{array}$} & \multicolumn{2}{c}{$\begin{array}{c}\text { Unit time per 5m } \\
\text { From data }\end{array}$} \\
Ground class & $m_{T_{1 m}}$ & $\sigma_{T 1 m}$ & $m_{T}$ & $\sigma_{T}$ & $m_{T}$ & $\sigma_{T}$ \\
\hline 3 & 0.28 & 0.31 & 1.4 & 1.1 & 1.4 & 1.1 \\
4 & 0.30 & 0.28 & 1.5 & 1.1 & 1.5 & 1.0 \\
5 & 0.64 & 0.63 & 3.2 & 1.9 & 3.2 & 1.8 \\
All classes & 0.37 & 0.42 & 1.8 & 1.5 & 1.8 & 1.5 \\
\hline
\end{tabular}

\subsection{Extraordinary events}

Extraordinary events (failures) are events that stop the excavation works for more than 15 days. In this section, we present the estimation of the failure rate and the probability distribution of the delay $D_{k}$ due to a failure based on historic data.

\subsubsection{Delay caused by a failure}

Project delays resulting from failures of the tunnel construction process are analyzed by Sousa (2010), using data from sixty-four failures for which such information was available. These delays are summarized in Figure 8. Only one case of a delay shorter than 2 months is reported in the database. It is likely that events leading to short delays were not reported by the questioned experts and were not stated in the available sources. To fit the distribution of the delay caused by one failure, $D_{k}$, we therefore assume that data on events causing a delay in the range of 15-60 days are missing. Furthermore, we assume that these events are frequent and that a shifted exponential distribution is therefore 
suitable to describe the delay $D_{k}$. The applied shifted exponential distribution is described by its CDF

$F_{D}(d ; \gamma)=1-\exp (-\gamma(d-15))$

where $\gamma$ is the parameter of the exponential distribution and $d$ is the delay in days. The observed delays from Sousa (2010) are provided as a histogram with thirteen intervals, $I_{1}=(15,60), I_{2}=(60,120), I_{3}=(120,180\rangle, \ldots, I_{13}=(720, \infty)$, shown in Figure 8. The lower limits of the intervals are denoted as $d_{1}^{L}, d_{2}^{L}, \ldots, d_{13}^{L}$; the number of observations in the intervals are denoted as $k_{1}, k_{2}, \ldots, k_{13}$. Because data from the first interval are missing, $k_{1}$ is unknown. To fit the probability distribution, the maximum likelihood method is applied to estimate the two unknown parameters: the parameter of the exponential distribution, $\gamma$, and the total number of delays, which is the sum of observations and missing records, $n_{\text {total }}=\sum_{i=1}^{i=13} k_{i}$. The likelihood function is formulated using the binomial distribution as follows:

$L\left(\gamma, n_{\text {total }} \mid k_{2}, \ldots, k_{13}\right)=\prod_{i=2}^{i=13}\left(\begin{array}{c}n_{\text {total }} \\ k_{i}\end{array}\right) p_{i} k_{i}\left(1-p_{i}\right)^{n_{o b s}-k_{i}}$

where $p_{i}$ is the probability of a sample falling into the $i$ th interval, which is determined from the exponential CDF of Eq. (9) as

$p_{i}=F_{D}\left(d_{i+1}^{L} ; \gamma\right)-F_{D}\left(d_{i}^{L} ; \gamma\right)$

The resulting fitted distribution of $D_{k}$ is depicted in Figure 8, together with the normalized data from Sousa (2010). The maximum likelihood estimates are $\gamma=$ 0.0062 day $^{-1}$ and $n_{\text {total }}=83$. The missing data from the first interval $I_{1}=(15,60\rangle$ therefore represent $24 \%$ of the cases. The mean and standard deviation of $D_{k}$ are 175 days and 160 days, respectively. 


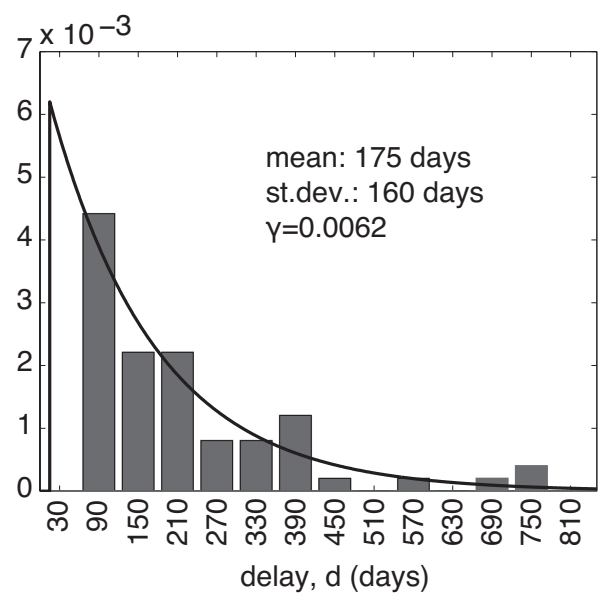

Figure 8. Distribution of delay, $D_{k}$, caused by one failure - data collected in Sousa (2010) and fitted shifted exponential distribution.

\subsubsection{Failure rate}

The failure rate $\lambda_{F_{i} \mid G_{i}, H_{i}}$ is defined as the number of failures (extraordinary events) per unit length of the tunnel tube. In the presented probabilistic model, it is defined conditionally on ground class $G_{i}$ and human factor $H_{i}$. Three different approaches are available for estimating the failure rate: expert judgment, reliability analysis or a statistical approach using data from constructed tunnels. Each of the approaches has its strengths and weaknesses. Ideally, multiple approaches should be employed and results should be compared and critically examined.

Expert estimations of probabilities of rare events are often unreliable (Kahneman and Tversky, 2000; Lin and Bier, 2008; Goodwin and Wright, 2010). They can be strongly biased by recent experiences of the expert. Such estimates should therefore be supported by other types of analyses and/or statistical data.

Reliability analysis of tunnel excavation processes is a complex task and, at present, is possible only with strong simplifications. Compared to the analysis of a completed structure, the analysis of a tunnel excavation process must take into account additional uncertainties connected to the construction process. One needs not only to analyze the reliability of the final tunnel, but also the reliability of each of the interim states of the process (different levels of support, different phases of excavation). Additionally, uncertainties resulting from the influence of human and organizational factors, which are 
of crucial importance during the construction process, are not included in common reliability analysis (Blockley, 1999).

To determine the failure rate $\lambda_{F_{i} \mid G_{i}, H_{i}}$ based on data, one must know the total number of failure events and the total length of excavated tunnels, ideally separately for individual ground classes. In this study, a rough estimate of $\lambda_{F_{j} \mid G_{i}, H_{i}}$ based on global data is made and compared with estimates using data from the Czech Republic. Because no information is available on the geological conditions and other features of the included tunnels, only the unconditional failure rate $\lambda_{F}$ is estimated. The most comprehensive database known to the authors is presented in Sousa (2010); other databases considered are HSE (2006), Seidenfuss (2006) and Stallmann (2005).

According to HSE (2006), tunnels with a total length of $8750 \mathrm{~km}$ were constructed in the years 1999-2004 worldwide, as summarized in Table 6. These data were collected from freely accessible websites; their accuracy is limited and their completeness cannot be verified. For this reason, the data reported for the Czech Republic by HSE (2006) is compared with detailed information from Barták (2007) and our own databases (Špačková, 2012). HSE (2006) reports construction of 29 tunnels with a total length of $59.6 \mathrm{~km}$ in the Czech Republic in the years 1999-2004. This number overestimates the length of constructed tunnel by $15 \%$ if parallel tunnel tubes are considered as separate tunnels and by $35 \%$ if parallel tubes are considered as one tunnel. Additionally, approximately $15 \%$ of the tunnels in the Czech republic are excavated by the cut\&cover method. Assuming that these shares apply also to the data in other countries, we reduce the total length of tunnels reported in HSE (2006) to estimate the total length of mined tunnels. The resulting estimates are shown in Table 6.

It is likely that many extraordinary events are missing in the available databases, because these include mainly major collapses reported by media or remembered by the interviewed experts. As evident from Section 3.2.1, at least $24 \%$ of extraordinary events can be considered as missing. The reported number of failures is therefore increased accordingly. The resulting estimates are shown in Table 6. These represent a lower bound, since more failures are likely to be missing in the databases. For example, failures from the Czech Republic, which are discussed below, are not included in any of the considered databases. Certainly there are more countries that are not included in the databases 
because of isolation of the local construction markets and language barriers. The estimated failure rate $\lambda_{F}$ reported in Table 6 is determined by dividing the estimated number of collapses with the estimated length of mined tunnels and is also a lower bound.

Table 6. Global data for assessment of failure rate, $\lambda_{F}$, from the years 1999-2004; using sources: HSE (2006), Seidenfuss (2006), Stallmann (2005) and (Sousa, 2010).

\begin{tabular}{cccccc}
\hline Type of tunnel & $\begin{array}{c}\text { Total length of } \\
\text { constructed tunnels } \\
\text { (HSE, 2006) }\end{array}$ & $\begin{array}{c}\text { Total length } \\
\text { of mined } \\
\text { tunnels } \\
\text { (estimate) }\end{array}$ & $\begin{array}{c}\text { Number of } \\
\text { collapses } \\
\text { (reported) }\end{array}$ & $\begin{array}{c}\text { Number of } \\
\text { collapses } \\
\text { (estimated lower } \\
\text { bound) }\end{array}$ & $\begin{array}{c}\lambda_{F} \\
\text { (estimated lower } \\
\text { bound) }\end{array}$ \\
\hline Road & $\sim 2000 \mathrm{~km}$ & $1320 \mathrm{~km}$ & 13 & 17 & $0.013 \mathrm{~km}^{-1}$ \\
Rail & $\sim 4200 \mathrm{~km}$ & $2770 \mathrm{~km}$ & 25 & 33 & $0.012 \mathrm{~km}^{-1}$ \\
Water/sewerage & $\sim 2100 \mathrm{~km}$ & $1390 \mathrm{~km}$ & 9 & 12 & $0.009 \mathrm{~km}^{-1}$ \\
Other & $\sim 450 \mathrm{~km}$ & $300 \mathrm{~km}$ & 1 & 1 & $0.003 \mathrm{~km}^{-1}$ \\
Total & $8750 \mathrm{~km}$ & $5750 \mathrm{~km}$ & 48 & 63 & $0.011 \mathrm{~km}^{-1}$ \\
\hline
\end{tabular}

Approximately $60 \mathrm{~km}$ of mined tunnels (incl. utility tunnels) have been constructed in the Czech Republic since 1990. In case of tunnels with several tubes, only the longest tube is considered, because in case of a tunnel collapse or other severe problems, construction of both tubes is likely to be stopped even if the collapse is considered as one failure. Since 1990, 14 severe collapses have been reported. The failure rate can be thus estimated as $0.23 \mathrm{~km}^{-1}$. Assuming that around $24 \%$ of cases were not reported, the failure rate rises to $0.31 \mathrm{~km}^{-1}$. This failure rate is almost 30 times higher than the failure rate computed from the global data.

A similar observation is made by Srb (2011), who compares the number of collapses and excavated tunnel lengths in the Czech Republic and Austria. The study reports 10 collapses in $35 \mathrm{~km}$ of road and railway tunnels in the Czech republic resulting in a failure rate of $0.29 \mathrm{~km}^{-1}$ and 8 collapses in $315 \mathrm{~km}$ of road and railway tunnels in Austria resulting in a failure rate of $0.023 \mathrm{~km}^{-1}$. 
The presented estimates show a huge spread and can only serve as a basis orientation for critical expert estimation.

\section{Application example}

The application of the DBN model is presented on the example of tunnel TUN3. First, an estimate of the total excavation time is carried out as would be done during the planning phase of the project. Second, this prediction is updated with the observed excavation time, i.e. with the data presented in Section 3.1. A scheme of the modeled tunnel is shown in Figure 9.

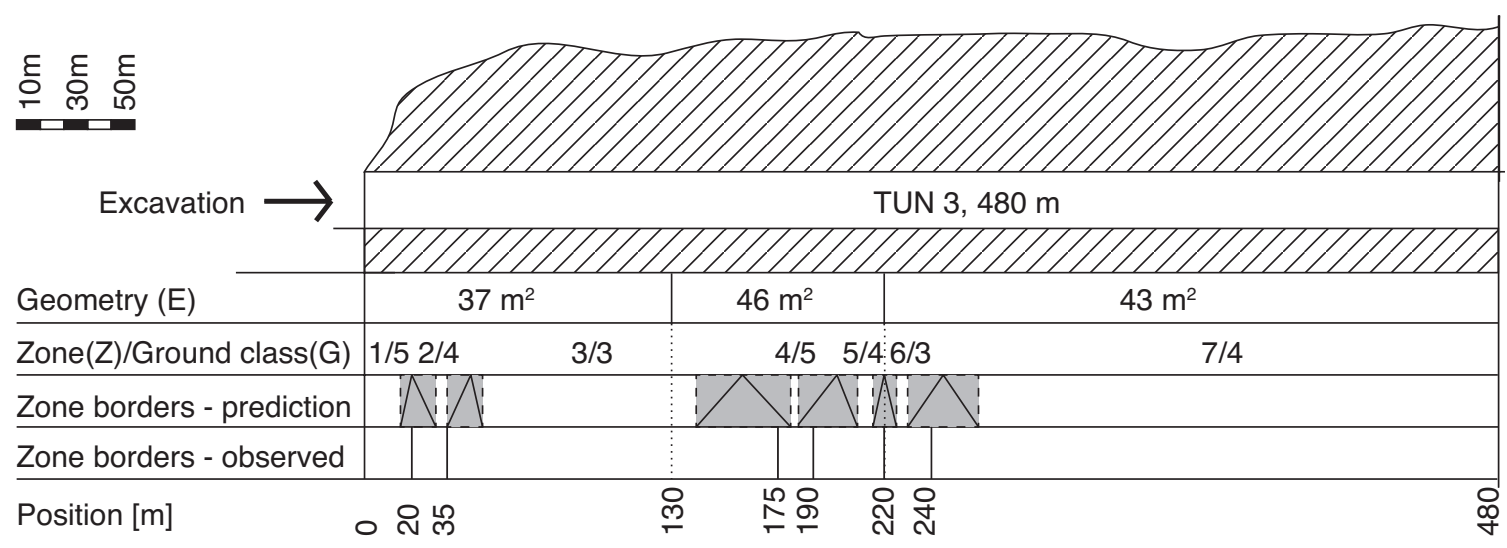

Figure 9. Scheme of the modeled tunnel TUN3. The predicted zone borders are modeled by triangular distributions.

The DBN used for prediction of the excavation time is depicted in Figure 10. The variables are summarized in the Table 7. Each slice of the DBN represents a tunnel segment with length $\Delta l=5 m$. i.e. the DBN has 96 slices in total. 


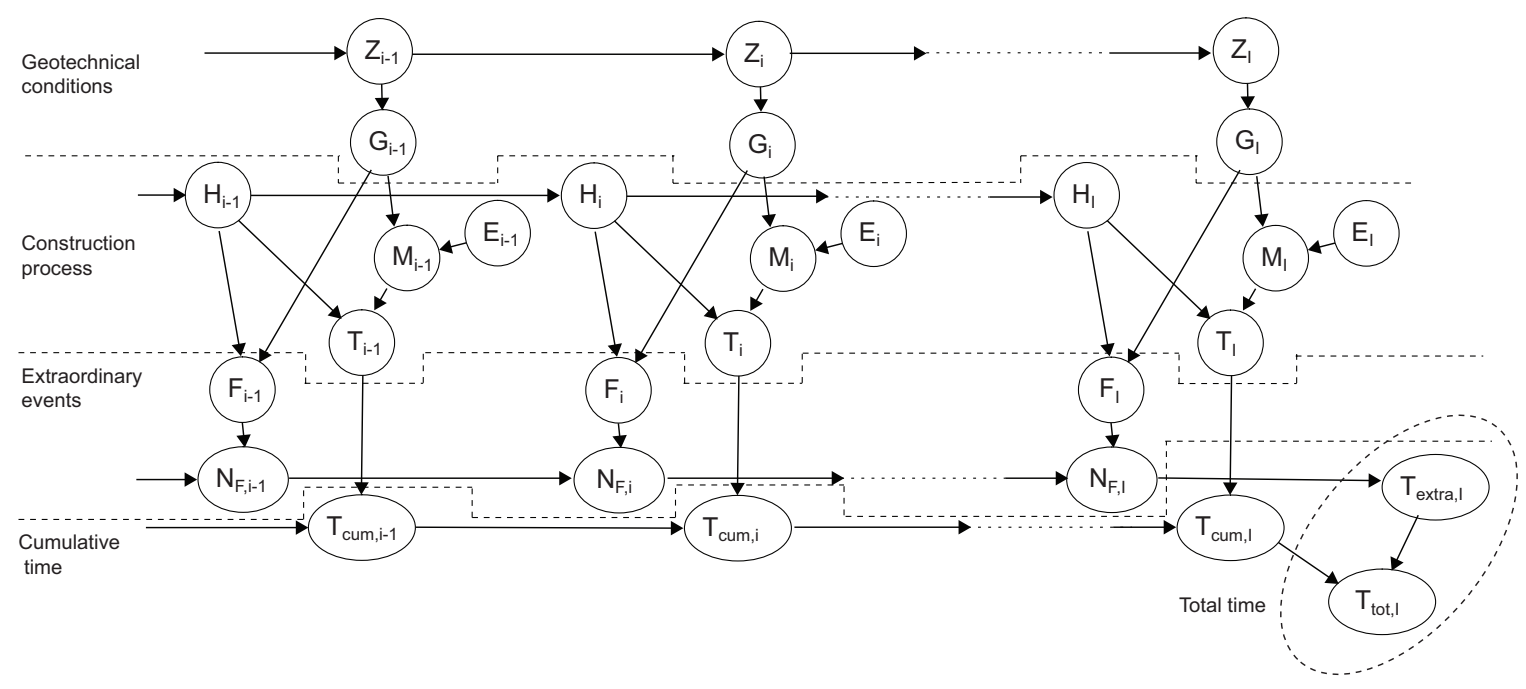

Figure 10. DBN model for prediction of total excavation time of the tunnel TUN3.

Table 7. Summary of variables of the DBN model for the prediction of the total excavation time of the tunnel TUN3.

\begin{tabular}{|c|c|c|c|}
\hline Id. & Variable & Type & States of the variable \\
\hline $\bar{Z}$ & Zone & Random/ Discrete & $1,2, \ldots, 7$ \\
\hline G & Ground class & Random/Discrete & $3,4,5$ \\
\hline $\mathrm{H}$ & Human factor & Random/Discrete & Favourable, neutral, unfavourable \\
\hline $\mathrm{E}$ & Geometry & Determ./Discrete & $37 \mathrm{~m}^{2}, 43 \mathrm{~m}^{2}, 46 \mathrm{~m}^{2}$ \\
\hline M & $\begin{array}{l}\text { Construction } \\
\text { method }\end{array}$ & Random/Discrete & $3-37,3-43,3-46,4-37,4-43,4-46,5-37,5-43,5-46$, \\
\hline $\mathrm{T}$ & Unit time & Random/ Discretized & $0, t_{\text {int }}, 2 t_{\text {int }}, \ldots, 14.5$ [days] $^{*}$ \\
\hline $\mathrm{F}$ & Failure mode & Random/Discrete & Failure, No failure \\
\hline $\mathrm{N}_{\mathrm{F}}$ & $\begin{array}{l}\text { Number of } \\
\text { failures }\end{array}$ & Random/Discrete & $0,1,2,3,>4$ \\
\hline $\mathrm{T}_{\text {cum }}$ & $\begin{array}{l}\text { Cumulative } \\
\text { time }\end{array}$ & Random/Discretized & $0, t_{i n t}, 2 t_{i n t}, \ldots, 1392^{* *}[$ days $]$ \\
\hline $\mathrm{T}_{\text {extra }}$ & $\begin{array}{l}\text { Delays caused } \\
\text { by failures }\end{array}$ & Random/ Discretized & $15, t_{\text {int }}, 2 t_{\text {int }}, \ldots, t_{\text {extra }, 99.9}\left[\right.$ days] ${ }^{* * *}$ \\
\hline $\mathrm{T}_{\text {tot }}$ & Total time & Random/ Discretized & $0, t_{\text {int }}, 2 t_{\text {int }}, \ldots,\left(1392+t_{\text {extra.99.9 }}[\right.$ days $]$ \\
\hline
\end{tabular}

${ }^{*} t_{i n t}$ is the discretization interval of time variables, $t_{i n t}=0.5$ day,

** upper bound of cumulative time $=96 \times 14.5=($ number of segments) $\mathrm{x}$ (upper bound of unit time)

${ }^{* * *} t_{\text {extra, } 99.9}$ is the 99.9 percentile of $\mathrm{T}_{\text {extra }}$

\subsection{Prediction of the tunnel excavation time in the planning phase}

The tunnel is divided into 7 zones represented by the variable $Z_{i}$. The positions of boundaries between the zones are uncertain in the planning phase of the project. It is represented by triangular distributions, which can be given by expert estimate based on the geological survey. For a given zone, the ground class $G_{i}$ is defined deterministically, 
i.e. in each zone either ground class 3,4 or 5 is to be expected. The height of overburden is considered directly through the variable $G_{i}$, it is not modeled by a separate variable in the DBN.

The geometry $E_{i}$ represents the cross-section area of the tunnel tube and is defined deterministically for each tunnel segment. No information is available on changes of the inclination of the tunnel, which varied up to $15^{\circ}$, and on the special tunnel support applied in the vicinity of existing structures. These parameters are thus not considered in this case study.

The construction method $M_{i}$ represents the excavation technology and support pattern used in segment $i$. Nine construction methods are defined conditionally on ground class $G_{i}$ and geometry $E_{i}$. For example, construction method " $3-37$ " is a method to be used in ground class 3 if the tunnel tube has a cross-section area of $37 \mathrm{~m}^{2}$. For all excavation methods, the full-face excavation is used. The primary support consists of rock bolts, 20 $\mathrm{cm}$ of shotcrete, two layers of meshes and lattice girders. Some characteristics of the construction methods (average round length and length and number of bolts) are summarized in Table 8.

The human factor $H_{i}$ can be in one of three states: "unfavourable, "neutral" and "favourable". A-priori, each of the states is assigned the same probability.

The unit time, $T_{i}$, is defined conditionally on construction method $M_{i}$ and human factor $H_{i}$. The conditional PDFs of unit time are described by the combined distribution of Eq. (2). The parameters of the distributions are assessed by the authors, the parameters of unit time for $H_{i}=$ "neutral" are summarized in Table 8. For $H_{i}=$ "favourable", the mean and standard deviations are reduced by $10 \%$, for $H_{i}=$ "unfavourable" they are increased by $10 \%$. 
Table 8. Parameters of the conditional probability distribution of unit time $T_{i}$ for different construction methods $M_{i}$ and for human factor $H_{i}=$ "neutral". $T_{N}$ is the unit time for normal performance, $T_{D}$ is the unit time for small disturbances, $p$ is the probability of normal performance.

\begin{tabular}{cccccccc}
\hline $\begin{array}{c}\text { Construction } \\
\text { method } M_{i}\end{array}$ & $\begin{array}{l}\text { Average } \\
\text { round } \\
\text { length } \\
{[\mathrm{m}]}\end{array}$ & $\begin{array}{l}\text { Bolts: } \\
\text { Length [m] } \\
\text { number per } \\
\text { round }\end{array}$ & $p$ & $\begin{array}{c}\text { Mean } \\
\text { of } T_{N}\end{array}$ & $\begin{array}{c}\text { St.dev. } \\
\text { of } T_{N}\end{array}$ & $\begin{array}{c}\text { Mean } \\
\text { of } T_{D}\end{array}$ & $\begin{array}{c}\text { St.dev. } \\
\text { of } T_{D}\end{array}$ \\
\hline $3-37$ & 1.6 & $3 / 4$ & 0.95 & 1.20 & 0.24 & 4.00 & 2.00 \\
$3-43$ & 1.6 & $3 / 4$ & 0.95 & 1.25 & 0.25 & 4.00 & 2.00 \\
$3-46$ & 1.7 & $3 / 4-12$ & 0.95 & 1.25 & 0.25 & 4.00 & 2.00 \\
$4-37$ & 1.5 & $4 / 6-7$ & 0.90 & 1.70 & 0.34 & 6.00 & 3.00 \\
$4-43$ & 1.5 & $3 / 4-7$ & 0.90 & 1.80 & 0.36 & 6.00 & 3.00 \\
$4-46$ & 1.3 & $3-4 / 4-7$ & 0.90 & 1.80 & 0.36 & 6.00 & 3.00 \\
$5-37$ & 1.0 & $4 / 6-7$ & 0.85 & 1.80 & 0.38 & 8.00 & 4.00 \\
$5-43$ & - & - & - & - & - & - & - \\
$5-46$ & 1.2 & $4 / 10$ & 0.85 & 1.90 & 0.38 & 8.00 & 4.00 \\
\hline
\end{tabular}

An example PDF of unit time for construction method 4-43 and $H_{i}=$ "neutral" is depicted in Figure 11.

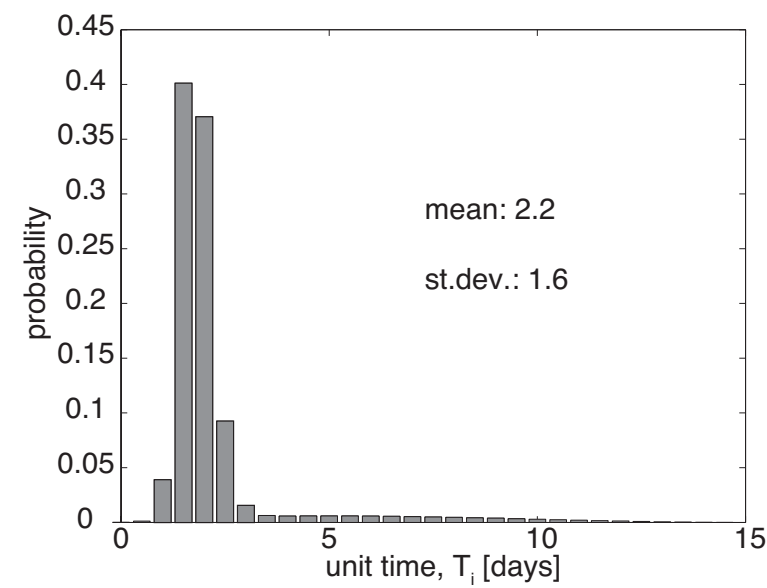

Figure 11. PDF of unit time per 5 m for construction method 4-43, $H_{i}=$ "neutral". 
The probability of variable $F_{i}$ being in state "failure" is determined on the basis of the failure rate analyzed in Section 3.2.2. The data analysis results in a broad interval of failure rate estimates; the values utilized for this case study (summarized in Table 9) are selected close to the lower bound of this interval, because TUN3 has smaller crosssection area and is constructed in relatively favorable geotechnical conditions. However, in real projects, a more thorough determination of the failure rate is recommendable, combining data analysis with expert knowledge and reliability analysis.

The probability distribution of a delay caused by one extraordinary event is the one estimated in Section 3.2.1 and shown in Figure 8.

Table 9. Failure rate in $\left[\mathrm{km}^{-1}\right]$ for different ground classes $G_{i}$ and human factors $H_{i}$.

\begin{tabular}{cccc}
\hline & $H_{i}=$ "unfav." & $H_{i}=$ "neutral" & $H_{i}=$ "favour." \\
\hline$G_{i}=3$ & 0.040 & 0.020 & 0.010 \\
$G_{i}=4$ & 0.060 & 0.030 & 0.015 \\
$G_{i}=5$ & 0.090 & 0.045 & 0.023 \\
\hline
\end{tabular}

The estimated progress of the tunnel excavation without consideration of extraordinary events, the cumulative time $T_{c u m, i}$ for all segments, is depicted in Figure 12. The uncertainty in the prediction is illustrated by the lines depicting the 5 th, 25 th, 50 th, 75 th and 95 th percentiles of the cumulative time at each position of the tunnel.

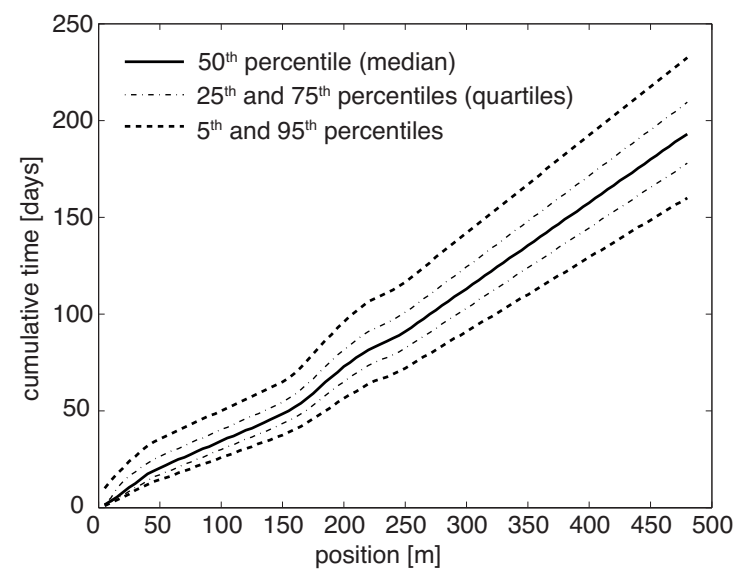

Figure 12. Estimated excavation progress for the $480 \mathrm{~m}$ long tunnel TUN3 - prior prediction in the planning phase. 
The estimated probability distributions of cumulative time $T_{c u m, i}$ and total time $T_{\text {tot }, i}$ for the whole tunnel, i.e. for $i=96$, are depicted in Figure 13. The estimated mean total excavation time equals 197 days, the estimated standard deviation is 38 days.

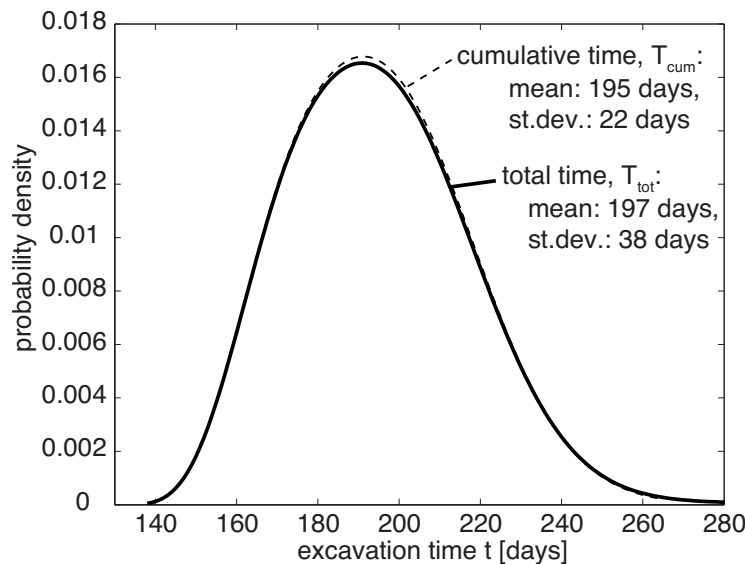

(a)

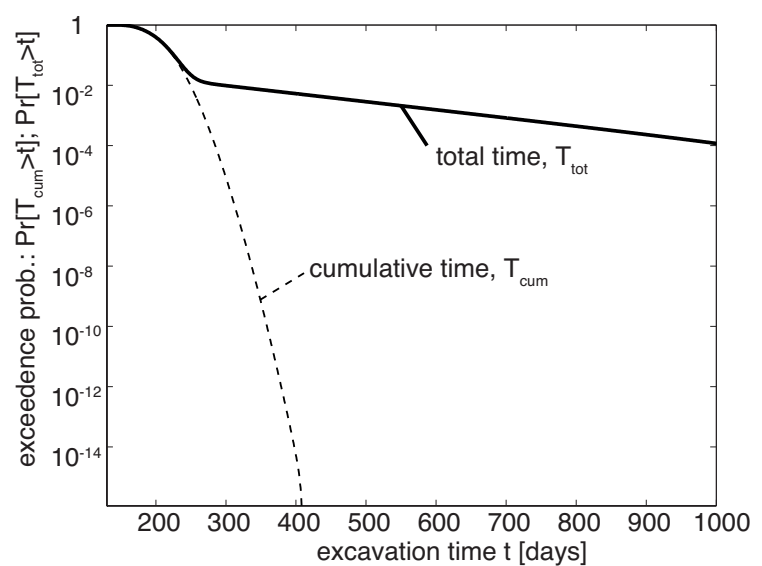

(b)

Figure 13. Prediction of construction time made during the whole tunnel TUN3. Probability distribution of cumulative time $T_{\text {cum }}$, which excludes extraordinary events, and total time $T_{\text {tot }}$, which includes extraordinary events. (a) Probability density functions; (b) exceedance probability.

The results show a small difference between the estimated mean cumulative time $T_{\text {cum }}$, which excludes the extraordinary events, and the mean total time $T_{\text {tot }}$, including the extraordinary events. The effect of extraordinary events is small because the probability that one or more such failures occur during the construction is only $\operatorname{Pr}\left(N_{f} \geq 1\right)=0.016$. Even with this small probability of failure, the standard deviation of construction time increases considerably when including the extraordinary events, which is also evident from the tail behavior shown in Figure 13b.

\subsection{Sensitivity analysis}

The effect of the variable human factor $H_{i}$ and the sensitivity of the results to the selected failure rate are shown in the Table 10. The first row in the table corresponds to the results presented in Section 4.1, where $H_{i}$ is uncertain and the failure rate is as shown in Table 9. The $2^{\text {nd }}$ to $4^{\text {th }}$ rows of the table show the estimates of total time for fixed values of $H_{i}$, i.e. for the case, when epistemic uncertainty in prior selection of the parameters of unit time 
and failure rate is not included. The last row of the table is computed with a failure rate that is 5 times higher than the one presented in Table 9.

Table 10. Sensitivity analysis of estimated total time, $T_{\text {tot }}$.

\begin{tabular}{llllc}
\hline Human factor $H_{i}$ & Failure rate & Mean & St.dev. & c.o.v. \\
\hline Uncertain & Acc. to Table 9 & 197 days & 38 days & $19 \%$ \\
$H_{i}=$ "unfavourable" & Acc. to Table 9 & 218 days & 43 days & $20 \%$ \\
$H_{i}=$ "neutral" & Acc. to Table 9 & 197 days & 32 days & $16 \%$ \\
$H_{i}=$ "favourable" & Acc. to Table 9 & 177 days & 24 days & $14 \%$ \\
Uncertain & 5x higher & 209 days & 73 days & $35 \%$ \\
\hline
\end{tabular}

\subsection{Updating of the prediction with observed performance}

The prediction of total excavation time can be updated in real-time with the excavation performance observed during the construction. For example, in the following the preliminary prediction is updated with the data observed during the excavation of the first $150 \mathrm{~m}$ of the tunnel TUN3. Observed variables are: the zone $Z_{i}$, the cumulative time $T_{c u m, i}$ and the number of failures $N_{F, i}$.

The observed boundaries of the zones are shown in Figure 9. No failures occur in the 150 long section and the cumulative time for excavating the section is 45 days, where the first zone is excavated in 9 days and the second zone in 5 days. The observed progress of the entire tunnel construction is shown in Figure 14, together with the mode of the a-priori prediction. 


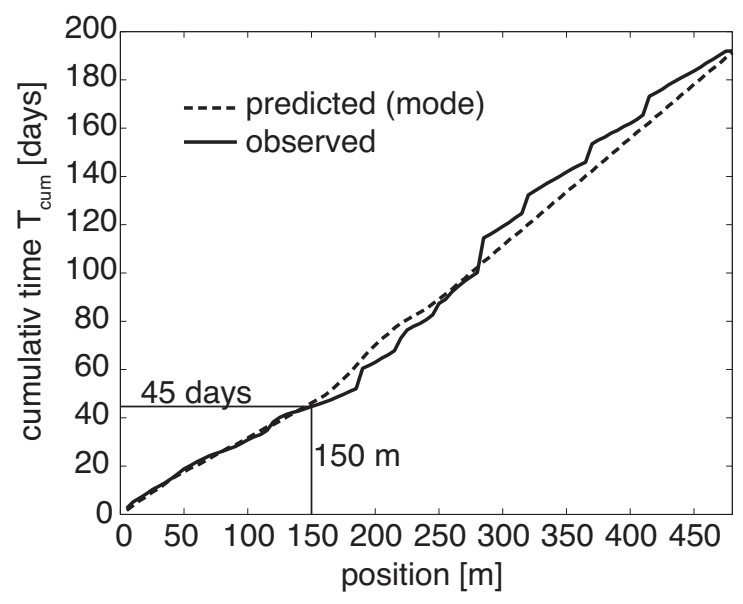

Figure 14. Predicted and observed cumulative time $T_{\text {cum }}$ in tunnel TUN3.

Two types of updating are carried out: (1) Bayesian updating of the probability distribution of human factor $H_{i}$ as described in Špačková and Straub (2012). (2) Bayesian updating of the conditional probability distribution of unit time $p\left(t_{i} \mid m_{i}, h_{i}\right)$ by means of fractional updating (Jensen and Nielsen, 2007) as described in Špačková (2012).

The estimated progress of the tunnel excavation updated with observations from the first $150 \mathrm{~m}$ is depicted in Figure 15.

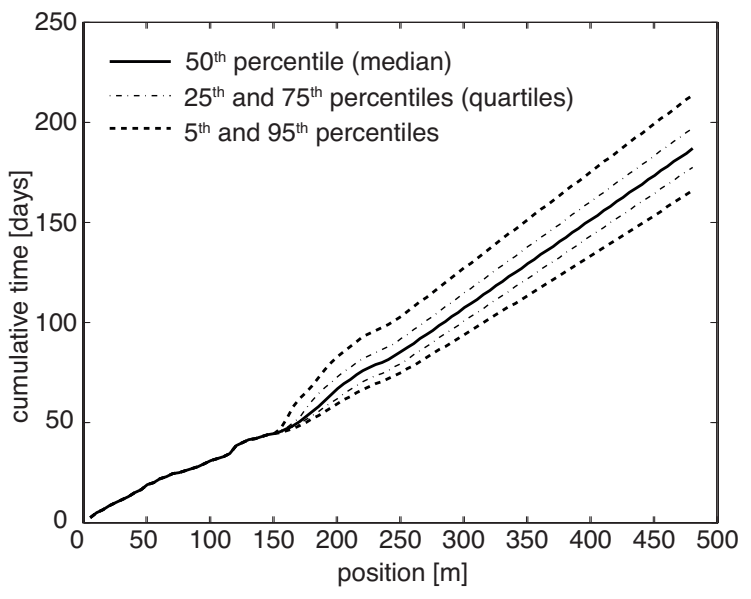

Figure 15. Estimated excavation progress for the tunnel TUN3; updated prediction based on the performance observed in the first $150 \mathrm{~m}$ of the tunnel.

By comparing Figure 15 with Figure 12, the reduction of the uncertainty in the prediction can be observed. This effect is depicted also in Figure 16, which compares the prior estimate of total time $T_{\text {tot }}$ for the whole tunnel with the updated estimate. 


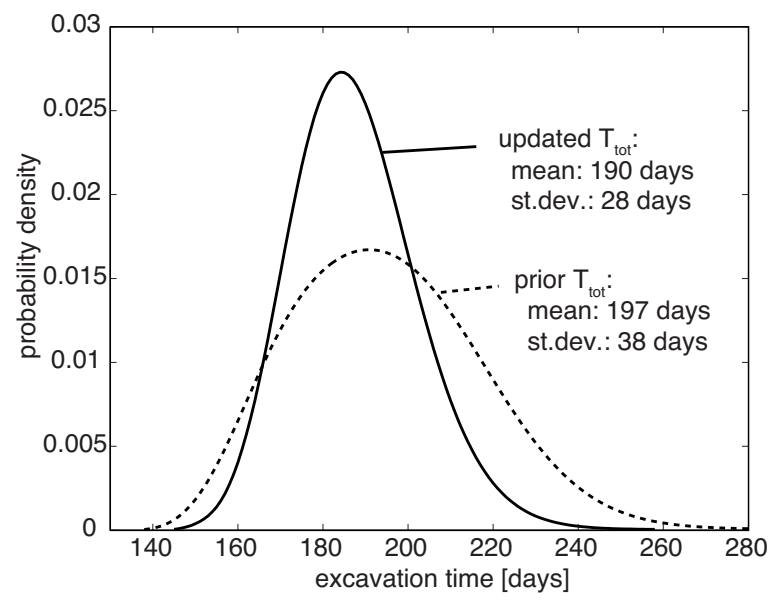

Figure 16. The total time $T_{\text {tot }}$ for tunnel the whole tunnel TUN3; original prediction and updated prediction based on the observed performance in the first $150 \mathrm{~m}$ of the tunnel.

Next, we demonstrate Bayesian updating of the estimate of the total time over the course of the entire construction phase. After excavation of each segment, an updated distribution of the total time $T_{\text {tot }}$ is computed, similar to the one shown in Figure 16. These updated distributions are shown in Figure 17 in a form of a contour plot. It can be observed that - on average - the uncertainty is reduced as the construction proceeds.

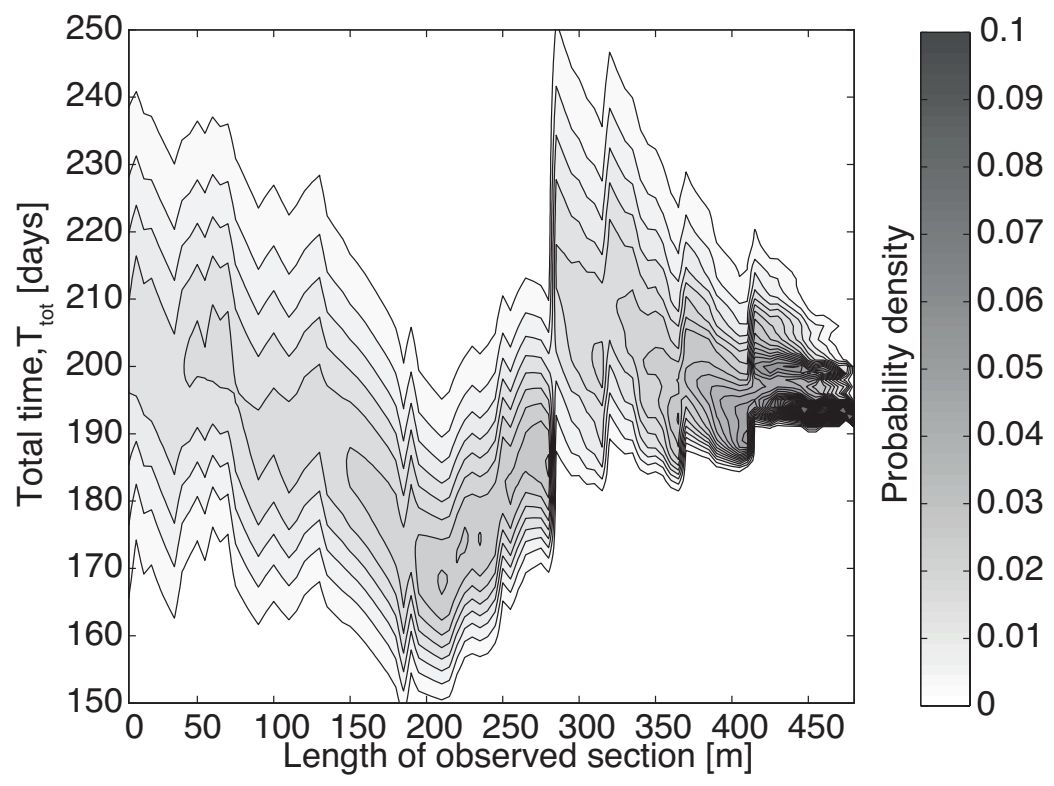

Figure 17. Contour plot of the distribution (PDF) of total time $T_{\text {tot }}$ for the entire tunnel TUN3 updated with observations from the excavated tunnel section, as a function of the construction progress. 
The jumps in the updated predictions in Figure 17 are caused by small disturbances observed during the construction process. The largest jump in the prediction can be observed after excavation of $280 \mathrm{~m}$ of the tunnel, where the excavation stopped for 13 days. If a delay is observed, the mean predicted total time increases suddenly. Additionally, the standard deviation of the prediction can increase after observing a delay, because the conditional probability of unit time $p\left(t_{i} \mid m_{i}, h_{i}\right)$ is updated and the probability of small disturbances increases and because the uncertainty in the human factor may increase.

The trends of the updated distribution of $T_{\text {tot }}$ in Figure 17 are related to the updated distribution of the human factor $H_{i}$, which is shown in Figure 18. It is recalled that $H_{i}$ takes the same value throughout the entire construction. However, its probability distribution changes throughout the construction as it is continuously updated with the observed performance. Note the correspondence between Figure 14 and Figure 18: When the excavation proceeds faster than originally predicted, i.e. where the increment of the cumulative time in most segments is smaller then the predicted one (e.g. in the last $200 \mathrm{~m}$ of the tunnel), the probability of a favorable human factor increases. Conversely, when the excavation proceeds slower, the probability of a favorable human factor decreases. The increased probability of an unfavorable human factor indicated in the early phases of the construction is caused by a slightly slower performance in the first segments of the tunnel.
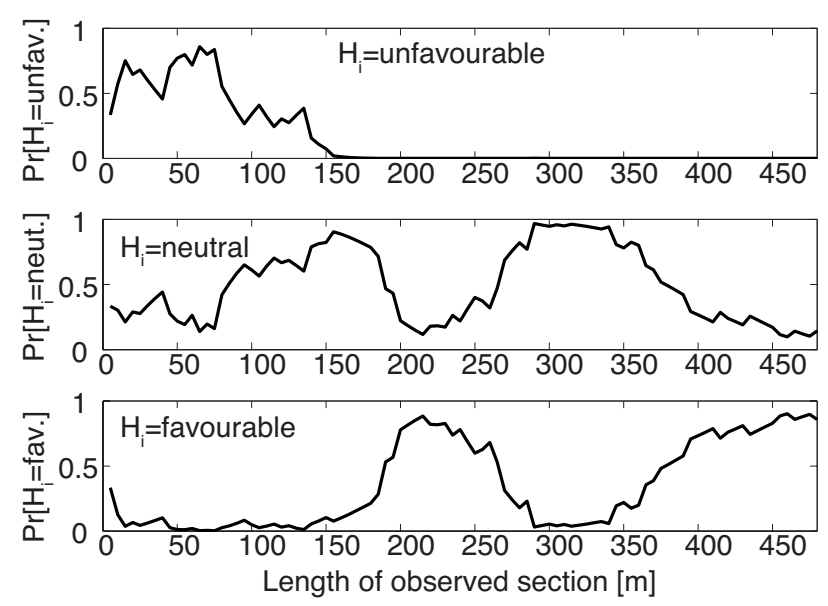

Figure 18. Updating of the variable human factor based on observed performance for tunnel TUN3, as a function of the construction progress. 


\section{Discussion}

The analysis of data from the excavation of three tunnels presented in Section 3.1 confirmed the assumption that three different phenomena can be distinguished in the construction process: (a) normal performance and (b) small disturbances of the construction process, which are both modeled within the variable unit time in the DBN model, and (c) extraordinary events or failures, which are modeled separately.

The analysis of tunnel performance from data of past projects must be performed separately for different utilized construction methods (excavation technology and support pattern). In the presented model framework, the construction method is defined through the ground class and tunnel geometry. Because in tunneling practice the definition of ground classes depends on the project-specific geotechnical classification system, they are not directly comparable among different projects. As a consequence, also the data are not directly transferable and a purely statistical approach to learning model parameters for prediction purposes is not feasible. The statistical analysis must be accompanied by a geological evaluation, which links the different classification systems.

To cover the many possible tunneling conditions, a large database of constructed tunnels would be needed. Therefore, the data presented in this paper cannot serve as a general database for probabilistic modeling of excavation performance in future tunnels. Section 3.1 of this paper however makes the following general contributions: (1) It presents a methodology for statistical analysis of tunnel performance data, which is broadly applicable. (2) It suggests a combined probability distribution (see Eq. (2)) for the unit time, which allows one to distinguish the normal performance from the small disturbances on a probabilistic basis without using expert judgment. These two types of uncertainties can thus be studied separately. (3) The obtained coefficients of variations and other parameters of the proposed combined distribution can serve as a basis for expert assessments used in future probabilistic models. The results in Section 3.1 show that small disturbances significantly influence the probability distribution of the unit time. When the estimates of the distribution of advance rates resp. unit time are made by experts, only the normal performance is modeled and the effect of small disturbances is commonly neglected. To assess the distribution of unit time realistically, the expert estimate should be combined with data: The experts assess the mean (mode) of the 
normal performance, which is strongly dependent on the individual conditions of the modeled tunnel; the variance of the normal performance and the probability distribution of small disturbances is assessed based on data from other tunnels.

The modeling of the extraordinary events during the construction process is arguably the most critical part in the probabilistic estimation of tunneling performance. The significant influence of the selected failure rate on the predicted excavation time is shown in Table 10. The failure rate has not been studied systematically in the past and cannot be assessed reliably from the available data, as discussed in Section 3.2. At present, available databases collect detailed information on selected observed extraordinary events. However, for the purpose of estimating failure rates, records of all extraordinary events within a clearly defined sample of tunnels would be needed. Such a sample could e.g. be all tunnels of a certain type in a specific region and time period. Ideally, additional information on geotechnical conditions and construction method should also be available in such a database. When modeling a specific tunnel construction, the statistical estimate of the failure rate should be accompanied by expert estimates and/or structural reliability analysis.

The utilization of the resulting statistical models for the probabilistic prediction of tunnel construction time using a DBN model is illustrated in the application example of Section 4. For the prior prediction during the design phase, the parameters of the DBN model are determined by expert assessments informed by the available data. During the construction, the prior prediction is updated using observed performance data. A significant part of the prior uncertainty is due to the epistemic uncertainty represented by the random variable human factor, which represents the deviation of the actual performance from the mean predicted performance. In the present model, this human factor is assumed to take on one value during the entire construction. The results of the case study indicate that a more refined model, which allows for different values of the human factor for different construction methods, might be more accurate. In spite of this, the results of Figure 17 show that the proposed model enables learning during the construction process.

The presented DBN model neglects additional time needed when changing construction methods and the influence of this additional time on the decisions about the changes. This omission is not critical in the presented application, because ground classes and the 
corresponding construction methods do not change frequently. However, this factor should be included in the future, e.g. following the approach presented by Sousa and Einstein (2012). The presented DBN model can be adjusted for modeling other processes than tunnel excavation, e.g. construction of tunnel lining or other linear construction processes. Additionally, construction costs can be included in the model by adding the corresponding variables to the DBN. When modeling construction costs, it is necessary to account for the dependency of some costs (e.g. labor costs, machinery costs) on construction time. However, research on cost models is hindered by the sensitivity of cost information and by the intricate system of cost monitoring and control.

\section{Conclusion}

A probabilistic model for estimation of tunnel construction time has been presented. The model takes into account the uncertainties in geotechnical conditions, excavation performance, and the risk of extraordinary events such as cave-in collapses. Additionally, it considers common factors (e.g. quality of planning, organization of the construction work), which systematically influence construction performance, and the epistemic uncertainty, i.e. the uncertainty in the expected construction progress due to incomplete knowledge in the planning phase. The model allows for efficient updating of the predictions based on observed excavation performance, as demonstrated by a case study of a $480 \mathrm{~m}$ long tunnel excavated by means of a conventional tunneling method.

To obtain realistic estimates, the model inputs should ideally be assessed using data from tunnels constructed in the past. A methodology for statistical analysis of excavation performance data is shown in this paper using records from three tunnels built using a conventional tunneling method. The results show that three types of effects can be observed in the construction performance: (1) normal performance, (2) small disturbances of the construction process, (3) extraordinary events. All of these phenomena have a significant impact on the construction time estimate. The probabilistic model inputs should thus combine the expert knowledge, which allows one to take into account the specifics of the modeled tunnel, with statistical analysis of data from tunnels constructed in the past, which realistically quantifies the variability of the construction performance, especially the effects of small disturbances and extraordinary events. 


\section{Acknowledgement}

The first and second authors are funded by project No. TA01030245 of the Technology Agency of the Czech Republic and project No. 1M0579 (CIDEAS research center) of the Ministry of Education, Youth and Sports of the Czech Republic. Additional support by DAAD and Bayhost is gratefully acknowledged.

\section{References}

Aliahmadi, A., Sadjadi, S., Jafari-Eskandari, M., 2011. Design a new intelligence expert decision making using game theory and fuzzy AHP to risk management in design, construction, and operation of tunnel projects (case studies: Resalat tunnel). The International Journal of Advanced Manufacturing Technology 53, 789-798.

Alvarez Grima, M., Bruines, P.A., Verhoef, P.N.W., 2000. Modeling tunnel boring machine performance by neuro-fuzzy methods. Tunnelling and Underground Space Technology 15, 259-269.

Barták, J., 2007. Underground construction in the Czech Republic. SATRA.

Barták, J., Makásek, P., 2011. Stability Time of the Unsupported Tunnel Excavation. Presented at the 39. konference zakládání staveb, Brno, pp. 162-168.

Benardos, A.G., Kaliampakos, D.C., 2004. Modelling TBM performance with artificial neural networks. Tunnelling and Underground Space Technology 19, 597-605.

Benjamin, J.R., Cornell, C.A., 1970. Probability, statistics, and decision for civil engineers. McGraw-Hill.

Bensi, M., Der Kiureghian, A., Straub, D., 2011. Bayesian network modeling of correlated random variables drawn from a Gaussian random field. Structural Safety 33, 317-332.

Bieniawski, Z.T., 1989. Engineering rock mass classifications: a complete manual for engineers and geologists in mining, civil, and petroleum engineering. WileyInterscience.

Blockley, D., 1999. Risk based structural safety methods in context. Structural Safety 21, 335-348.

Burbaum, U., Krajewski, W., Seeger, K.J., 2005. Wirtschaftliche Aspekte bei Tunnelbauwerken in frühen Planungsphasen. Hessische Straßen- und Verkehrsverwaltung.

Cheung, S.H., Beck, J.L., 2010. Calculation of Posterior Probabilities for Bayesian Model Class Assessment and Averaging from Posterior Samples Based on Dynamic System Data. Computer - Aided Civil and Infrastructure Engineering 25, 304321.

Chou, J.-S., 2011. Cost simulation in an item-based project involving construction engineering and management. International Journal of Project Management 29, 706-717. 
Chung, T.H., Mohamed, Y., AbouRizk, S., 2006. Bayesian Updating Application into Simulation in the North Edmonton Sanitary Trunk Tunnel Project. Journal of Construction Engineering and Management 132, 882-894.

Codetta-Raiteri, D., Bobbio, A., Montani, S., Portinale, L., 2012. A dynamic Bayesian network based framework to evaluate cascading effects in a power grid. Engineering Applications of Artificial Intelligence 25, 683-697.

Der Kiureghian, A., Ditlevsen, O., 2009. Aleatory or epistemic? Does it matter? Structural Safety 31, 105-112.

Einstein, H.H., 1996. Risk and risk analysis in rock engineering. Tunnelling and Underground Space Technology 11, 141-155.

Eskesen, D.S., Tengborg, P., Kampmann, J., Veicherts, H.T., 2004. Guidelines for tunnelling risk management: International Tunnelling Association, Working Group No. 2. Tunnelling and Underground Space Technology 19, 217-237.

Faber, M.H., Straub, D., Heredia-Zavoni, E., Montes-Iturrizaga, R., 2012. Risk assessment for structural design criteria of FPSO systems. Part I: Generic models and acceptance criteria. Marine Structures 28, 120-133.

Flyvbjerg, B., COWI, 2004. Procedures for Dealing with Optimism Bias in Transport Planning, Guidance document of The British Department for Transport ( No. 58924).

Flyvbjerg, B., Holm, S.M.K., Buhl, S.L., 2004. What Causes Cost Overrun in Transport Infrastructure Projects? Transport Reviews 24, 3-18.

Goodwin, P., Wright, G., 2010. The limits of forecasting methods in anticipating rare events. Technological Forecasting and Social Change 77, 355-368.

Grasso, P., Xu, S., Pescara, M., Russo, G., Repetto, L., 2006. A Methodology for the Geotechnical Design of Long High-Speed Rail Tunnels Under the Conditions of Uncertainty. Presented at the China International Symposium on HighSpeed Railway Tunnels Exhibition, Beijing, China.

Hong, E.-S., Lee, I.-M., Shin, H.-S., Nam, S.-W., Kong, J.-S., 2009. Quantitative risk evaluation based on event tree analysis technique: Application to the design of shield TBM. Tunnelling and Underground Space Technology 24, 269-277.

HSE (Health \& Safety Executive), 2006. The risk to third parties from bored tunnelling in soft ground - research report 453. Health \& Safety Executive, HSE Books, Sudbury, Suffolk, GB.

IMIA (The International Association of Engineering Insurers), 2006. ALOP/DSU coverage for tunnelling risks? Presented at the The International Association of Engineering Insurers 39th Annual Conference, Boston.

Isaksson, T., Stille, H., 2005. Model for Estimation of Time and Cost for Tunnel Projects Based on Risk Evaluation. Rock Mechanics and Rock Engineering 38, 373-398.

ITA (International Tunnelling Association), 2009. General report on conventional tunnelling method ( No. 002).

ITIG (International Tunnelling Insurance Group), 2006. A code of practice for risk management of tunnel works.

Jensen, F.V., Nielsen, T.D., 2007. Bayesian networks and decision graphs. Springer. 
Jurado, A., De Gaspari, F., Vilarrasa, V., Bolster, D., Sánchez-Vila, X., Fernàndez-Garcia, D., Tartakovsky, D.M., 2012. Probabilistic analysis of groundwater-related risks at subsurface excavation sites. Engineering Geology 125, 35-44.

Kahneman, D., Tversky, A., 2000. Choices, Values, and Frames. Cambridge University Press.

Kim, Y., Bruland, A., 2009. Effect of rock mass quality on construction time in a road tunnel. Tunnelling and Underground Space Technology 24, 584-591.

Lin, S.-W., Bier, V.M., 2008. A study of expert overconfidence. Reliability Engineering \& System Safety 93, 711-721.

Lombardi, G., 2001. Geotechnical risks for project financing of tunnels in non-urban areas. Tribune No 20 - International Tunnelling Association newsletter.

Min, S., 2003. The application of "Decision Aids for Tunneling (DAT)" to the Sucheon tunnel in Korea (Master thesis, MIT, Boston).

Min, S., Kim, T.K., Lee, J.S., Einstein, H.H., 2008. Design and construction of a road tunnel in Korea including application of the Decision Aids for Tunneling - A case study. Tunnelling and Underground Space Technology 23, 91-102.

Moret, Y., Einstein, H.H., 2011. Cost and time correlations in linear infrastructure construction, in: Applications of Statistics and Probability in Civil Engineering. Presented at the ICASP, Zürich, pp. 788-796.

Murphy, K.P., 2002. Dynamic Bayesian Networks Representation, Inference and Learning (Doctoral thesis, Univ. of California, Berkeley.).

Ökmen, Ö., Öztaş, A., 2008. Construction Project Network Evaluation with Correlated Schedule Risk Analysis Model. Journal of Construction Engineering and Management 134, 49-63.

Reilly, J., 2005. Cost estimating and risk - management for underground projects, in: Erdem, Y., Solak, T. (Eds.), Underground Space Use. Analysis of the Past and Lessons for the Future. Taylor \&amp; Francis.

Ruwanpura, J., Ariaratnam, S., 2007. Simulation modeling techniques for underground infrastructure construction processes. Tunnelling and Underground Space Technology 22, 553-567.

Said, H., Marzouk, M., El-Said, M., 2009. Application of computer simulation to bridge deck construction: Case study. Automation in Construction 18, 377-385.

Sapigni M., Berti M., Bethaz E., Busillo A., Cardone G., 2002. TBM performance estimation using rock mass classifications. International Journal of Rock Mechanics and Mining Sciences 39, 771-788.

Seidenfuss, T., 2006. Collapses in Tunnelling, Mater thesis. (Master thesis, Fachhochschule Stuttgart - Hochschule für Technik).

Shahriar, K., Sharifzadeh, M., Hamidi, J.K., 2008. Geotechnical risk assessment based approach for rock TBM selection in difficult ground conditions. Tunnelling and Underground Space Technology 23, 318-325.

Singh, B., Goel, R.K., 1999. Rock mass classification: a practical approach in civil engineering. Elsevier.

Sousa, R.L., 2010. Risk analysis for tunneling projects (Doctoral thesis, MIT, Boston). 
Sousa, R.L., Einstein, H.H., 2012. Risk analysis during tunnel construction using Bayesian Networks: Porto Metro case study. Tunnelling and Underground Space Technology 27, 86-100.

Špačková, O., 2012. Risk management of tunnel construction projects: Modelling uncertainty of construction time (cost) estimates for risk assessment and decisionmaking. (Doctoral thesis, Czech Technical University, Prague).

Špačková, O., Straub, D., 2011. Probabilistic risk assessment of excavation performance in tunnel projects using Bayesian networks: a case study, in: Proceedings of the 3rd International Symposium on Geotechnical Safety and Risk. Bundesanstalt für Wasserbau, München, pp. 651-660.

Špačková, O., Straub, D., 2012. Dynamic Bayesian network for probabilistic modeling of tunnel excavation processes. Computer-Aided Civil and Infrastructure Engineering in print.

Srb, M., 2011. Possibilities of the collapse reduction during the excavation of conventional tunnels in the Czech republic.

Stallmann, M., 2005. Verbrüche im Tunnelbau, Ursachen und Sanierung.

Straub, D., Der Kiureghian, A., 2010. Bayesian Network Enhanced with Structural Reliability Methods: Application. Journal of Engineering Mechanics 136, 12591270.

van Dorp, J.R., 2005. Statistical dependence through common risk factors: With applications in uncertainty analysis. European Journal of Operational Research $161,240-255$.

Vanmarcke, E., 1983. Random Fields: Analysis and Synthesis. The MIT Press.

Yang, I., 2007. Risk Modeling of Dependence among Project Task Durations. Computer - Aided Civil and Infrastructure Engineering 22, 419-429. 


\section{APPENDIX 1: Introduction to Bayesian networks.}

Bayesian networks (BNs) are graphical models representing a set of random variables. The variables are represented by nodes of the BN, the links stand for the stochastic dependencies between the variables. The $\mathrm{BN}$ concept is in the following introduced through the example given in Figure 19.

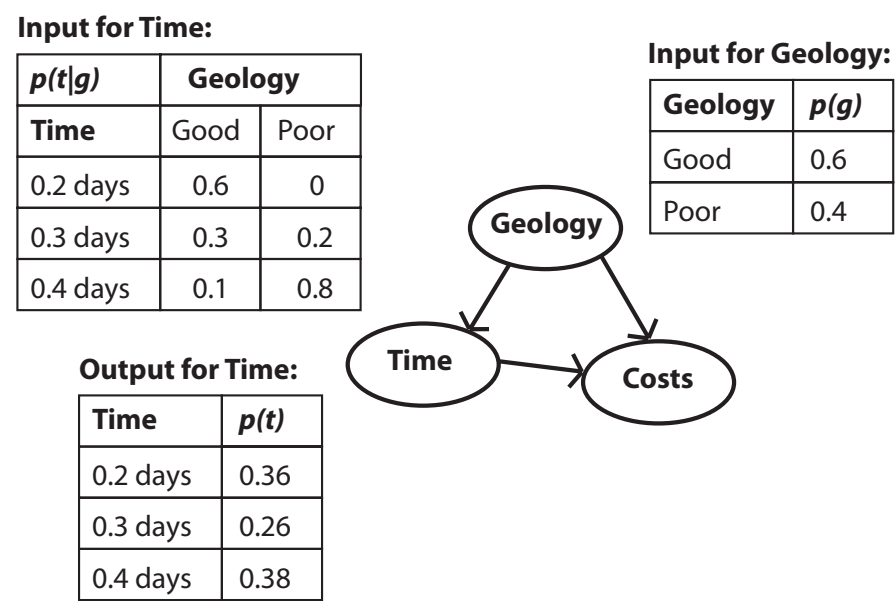

Figure 19. Sample Bayesian network (BN). The tables show the conditional probability table $(C P T)$ of time given geology, the marginal probability mass function (PMF) of geology and the resulting marginal PMF of time.

The BN contains three random variables: Geology $G$, time for excavation of a tunnel segment $T$ and costs of excavation of a tunnel segment $C$.

In this simplified example, Geology $G$ can be in one of two states "good" or "poor" with probabilities $\operatorname{Pr}(G=$ "good" $)=0.6$ and $\operatorname{Pr}(G=$ "poor" $)=0.4$. Excavation time $T$ can be in one of three states and it is defined conditionally on the geology. For example the probability $\operatorname{Pr}(T=0.2 \mid G=$ "good" $)=0.6$ represents the conditional probability of time being 0.2 days on the condition that the geology is good. The variable cost $C$ is defined conditionally on both geology $G$ and time $T$.

The whole DBN is fully described by the joint probability mass function (PMF), which is computed using the chain rule:

$p(g, t, c)=p(g) p(t \mid g) p(c \mid g, t)$ 
where the $p(g)$ is the PMF of $G, p(t \mid g)$ is the conditional PMF of $T$ given $G$ and $p(c \mid g, t)$ is the conditional PMF of $C$ given $G$ and $T$. The notation used here applies to discrete random variables, which is the case for the model proposed in this paper. We use $p(g)$ as the short notation for $p_{G}(g)$ and similarly $p(t \mid g)$ for $p_{T \mid G}(t \mid g)$. The conditional probabilities defining the $\mathrm{BN}$ are organized in so-called conditional probability tables (CPTs); an example of the CPT of time $T, p(t \mid g)$, is shown in Figure 19. The geology $G$ is specified unconditionally by its PMF $(g)$, as it has no parent variable.

Commonly we are interested in the marginal probability distribution of selected variables. For example, the marginal distribution of time $T, p(t)$, which is also shown in Figure 19, can be calculated as follows:

$$
\begin{array}{r}
p(t)=\sum_{G} \sum_{C} p(g, t, c)=\sum_{G} \sum_{C} p(g) p(t \mid g) p(c \mid g, t) \\
=\sum_{G} p(g) p(t \mid g) \sum_{C} p(c \mid g, t)=\sum_{G} p(g) p(t \mid g)
\end{array}
$$

For the specific example of Figure 19, this can be written explicitly as

$$
\begin{aligned}
& \operatorname{Pr}(T=0.2)=\operatorname{Pr}(T=0.2 \mid G=\text { "good" }) * \operatorname{Pr}(G=\text { "good" })+\operatorname{Pr}(T=0.2 \mid G= \\
& \text { "poor" }) * \operatorname{Pr}(G=\text { "poor" })=0.6 * 0.6+0 * 0.4=0.36,
\end{aligned}
$$

where $\operatorname{Pr}(T=0.2)$ is the probability of excavation time being in state 0.2 . The probability of time $T$ being in other states is calculated accordingly.

The graphical nature of the $\mathrm{BN}$ is useful for representing and communicating the assumptions made in probabilistic models. Additionally, well-developed procedures for updating the BNs with additional information exist. The possibility to update the predictions is one of the main advantages of the $\mathrm{BN}$ models over $\mathrm{MC}$ simulation, where this possibility is limited. The reader interested in a more thorough introduction to $\mathrm{BN}$ is referred to Jensen and Nielsen (2007). Applications of BNs in engineering are presented for example in Straub and Der Kiureghian (2010), Bensi et al. (2011), Faber et al. (2012) or Codetta-Raiteri et al. (2012). 


\section{APPENDIX 2: Advance rate and unit time as random processes}

The unit time $T$ and the advance rate $A$ can be regarded as random processes. We first discuss the advance rate that is commonly used in tunneling practice. The advance rate is defined as

$A(t)=\frac{d X(t)}{d t}$

where $X(t)$ is the location of the tunnel heading at time $t$. In practice, $X(t)$ can be measured only at discrete points in time. If measurements are made every $\Delta t$, the corresponding advance rate is calculated as

$A_{\Delta t}(t)=\frac{X(t)-X(t-\Delta t)}{\Delta t}$

$A$ and $A_{\Delta t}$ are related by:

$A_{\Delta t}(t)=\frac{1}{\Delta t} \int_{t-\Delta t}^{t} A(t) d t$

If the tunnel advance rate is a homogenous process, then $A$ and $A_{\Delta t}$ will be the same in the mean. However, the variance of $A_{\Delta t}$ differs from that of $A$ and is (Vanmarcke, 1983):

$\sigma_{A_{\Delta t}}^{2}=\operatorname{Var}\left[\frac{1}{\Delta t} \int_{0}^{\Delta t} A(t) d t\right]$

$=\sigma_{A}^{2} \cdot \frac{2}{\Delta t} \int_{0}^{\Delta t}\left(1-\frac{t}{\Delta t}\right) \rho_{A}(t) d t$

$=\sigma_{A}^{2} \cdot \gamma(\Delta t)$

where $\sigma_{A}^{2}$ is the variance and $\rho_{A}$ is the correlation function of the random process $A(t)$. $\gamma(\Delta t)=\frac{2}{\Delta t} \int_{0}^{\Delta t}\left(1-\frac{t}{\Delta t}\right) \rho_{A}(t) d t$ is the so-called variance function of the random process, which depends on the correlation function. For the special case of an uncorrelated process 
$\gamma(\Delta t)=0$; for a fully correlated process $\gamma(\Delta t)=1$. In other cases, the variance function decreases with increasing $\Delta t$.

The square root of the variance function is a reduction factor, which is applied to reduce the standard deviation corresponding to a fully correlated process, similar to the approach presented in Isaksson and Stille (2005). The standard deviation for the advance rate measured over any time $\Delta t$ can be determined by

$\sigma_{A_{\Delta t}}=\sigma_{A_{r e f}} \sqrt{\frac{\gamma(\Delta t)}{\gamma\left(\Delta t_{r e f}\right)}}$

where $\sigma_{A_{r e f}}$ is the standard deviation of the advance rate measured over a reference time $\Delta t_{\text {ref }}$.

Eq. (16) and Eq. (17) give rise to the averaging effect: The variance of $A_{\Delta t}$ becomes smaller as $\Delta t$ increases. This must be accounted for when estimating the advance rate from observations. However, in practice this effect is often neglected when advance rates are estimated by experts, which can lead to significant under- or overestimation of the uncertainty.

In the DBN model, unit time $T$ is utilized instead of the advance rate. It is defined as

$T_{i}=t\left(x_{i}\right)-t\left(x_{i}-\Delta l\right)$

where $t(x)$ is the time the tunnel heading passes the position $x$ and $\Delta l$ is the length of a tunnel segment.

For a homogenous process, the mean $m_{T}$ of unit time increases linearly with $\Delta l$ :

$m_{T}=\frac{\Delta l}{\Delta l_{\text {ref }}} m_{T_{r e f}}$

where $m_{T_{r e f}}$ is the mean of the unit time $T_{r e f}$ for a reference length $\Delta l_{r e f}$.

The standard deviation of the $T_{i}$ is also a function of $\Delta l$. In analogy to Eq. (18) it can be expressed as a function of the standard deviation $\sigma_{T_{r e f}}$ of the unit time $T_{\text {ref }}$ for a reference length $\Delta l_{\text {ref }}$, as follows: 
$\sigma_{T}=\frac{\Delta l}{\Delta l_{\text {ref }}} \sigma_{T_{r e f}} \sqrt{\frac{\gamma(\Delta l)}{\gamma\left(\Delta l_{r e f}\right)}}$

where the variance function is:

$\gamma(\Delta l)=\frac{2}{\Delta l} \int_{0}^{\Delta l}\left(1-\frac{x}{\Delta l}\right) \rho_{T}(x) d x$

and $\rho_{T}$ is the correlation function of the unit time. Example correlation functions of unit time obtained from data are presented in Section 3.1.3. 